\title{
Title: Predicting Bird Distributions Under Global Change
}

\section{Authors \& Affiliations:}

MacPherson $^{1}$, M.P., Burgio ${ }^{2,3}$, K.R., DeSaix ${ }^{4}$, M.G., Freeman ${ }^{5}$, B.G., Herbert ${ }^{6}$, J., Herman ${ }^{7}$, R., Jirinec $^{8}$, V., Shonfield ${ }^{9}$, J., Slager ${ }^{10}$, D.L., van Rees ${ }^{11}$, C.B., and J.E. Jankowski ${ }^{5}$

1. Louisiana State University Museum of Natural Sciences, Louisiana State University, Baton Rouge, LA, USA

2. New York City Audubon Society, New York, NY, USA

3. Department of Ecology and Evolutionary Ecology, University of Connecticut, Storrs, CT, USA

4. Department of Biology, Colorado State University, Fort Collins, CO, USA

5. Biodiversity Research Centre and Department of Zoology, University of British Columbia, Vancouver, BC, Canada

6. Ecology and Evolutionary Biology, Tulane University, New Orleans, LA, USA

7. Department of Ecology and Evolution, Stony Brook University, NY

8. School of Renewable Natural Resources, Louisiana State University and LSU AgCenter, Baton Rouge, LA, USA

9. LGL Limited, Cambridge, ON, Canada

10. Department of Biology, University of Washington, Seattle, WA, USA

11. River Basin Center \& Odum School of Ecology, University of Georgia

\section{Author Contributions:}

Maggie MacPherson - concept, symposium organizer, symposium participant, writing \& revising, editing full manuscript, topic editor (abstract, theory) and co-editor (temporal resolution of data types), figures, tables.

Kevin R. Burgio - concept, overall project support, symposium participant, writing \& revising, conceptualizing and constructing figures, editing full manuscript, topic co-editor (methods \& data types for spatial data)

Matthew G. DeSaix - symposium participant, writing \& revising, topic co-editor (temporal resolution of data types)

Ben Freeman - symposium participant, writing, publication approach/ideas, topic editor (discussion)

Vitek Jirinec - symposium participant, writing \& revising, topic co-editor (logistical methods and data types for occurrence data), figures.

John Herbert - symposium participant, writing, topic co-editor (methods \& data types for spatial data)

Julia Shonfield - symposium participant, writing \& revising, topic editor (introduction) 
bioRxiv preprint doi: https://doi.org/10.1101/2021.05.26.445867; this version posted May 27, 2021. The copyright holder for this preprint (which

was not certified by peer review) is the author/funder, who has granted bioRxiv a license to display the preprint in perpetuity. It is made available under aCC-BY-NC 4.0 International license.

David Slager - symposium participant, writing \& revising, topic editor (literature cited), topic co-editor (logistical methods and data types for occurrence data)

Rachael Herman - writing, topic co-editor (logistical methods and data types for occurrence ddata)

Charles van Rees - writing \& revising, topic editor (analytical methods), figures.

Jill Jankowski - concept, symposium participant, writing \& revising, editing full manuscript 


\section{ABSTRACT}

2 Global change creates an urgent need to predict spatial responses of biota to support the

3 conservation of sufficient habitat to maintain biodiversity. We present species distribution model

4 theory and a synthesis of avian literature on approaches to collecting occurrence data, selecting

5 explanatory variables and analytical processes currently in use to predict future distributions. We

6 find that interpreting the validity of current predictive distributions is hindered by variation in

7 spatio-temporal resolution of data sets that force hypothesis testing under the Grinnellian niche

8 concept. Broadly, the capacity of species to shift their geographic ranges under land use and

9 climate change is expected to be limited by both large scale (i.e., the physiological or

10 fundamental niche) and small scale (i.e., the realized or tolerance niche) factors. We highlight the

11 strengths and weaknesses of widely used explanatory variables and analytical approaches

12 tailored to macrohabitat characteristics and the Grinnellian niche concept. This synthesis

13 addresses if and how current approaches align with theory and makes recommendations for

14 future directions to improve the accuracy of predictive distribution modelling.

16 KEY WORDS: species distribution model, environmental niche model, predictive distribution

17 modeling, global change, climate change.

\section{INTRODUCTION}

20 Anthropogenic pressures on climate and land cover lead to altered ecosystems across, and have

21 consequences for the geography of species distributions (Parmesan \& Yohe, 2003). This creates

22 an urgent need for understanding species spatial responses to global change and ensuring

23 conservation of suitable habitat that supports population persistence and conserves biodiversity. 
24 The accuracy of current predictive species distribution models, however, is limited due to

25 variation in temporal and spatial resolution of datasets. The capacity of species to change their

26 geographic ranges is limited by both large-scale factors (i.e., things that distinguish range-wide

27 patterns like temperature and rainfall patterns - macrohabitat) and small-scale factors (i.e., things

28 that drive responses by individuals like biotic interactions and resource availability -

29 microhabitat). In this review, we explore the utility of predictive distribution modelling in

30 guiding conservation action in birds. We focus on avian biodiversity because birds are excellent

31 indicators of environmental change, may be more vulnerable to climate change than some other

32 taxa (e.g., mammals), and they have the most widespread and in-depth databases on distributions

33 (Morrison, 1986; Riddell et al., 2021). Insights from avian literature may also be generalizable to

34 other taxa because birds display a wide variety of life history strategies, and citizen science

35 initiatives and long-term research programs have yielded an abundance of predictive distribution

36 literature (Şekercioğlu et al., 2019).

37 A multitude of factors can ultimately influence how species, populations and individuals

38 respond to changing climate regimes. Individuals may lack flexibility in tracking relevant

39 environmental cues to adjust the timing of life history events and to accommodate novel

40 ecological circumstances. Alternatively, even when species are flexible in timing life history

41 events, they may be unable to modulate behavior in response to environmental anomalies that

42 affect recruitment. For example, advancing egg laying dates to match earlier spring warming

43 temperatures may have negative consequences for nestling survival when the chances of cold

44 snaps are decoupled from warming trends caused by climate change (Shipley et al., 2020).

45 Predicting how species distributions could be altered (shift, contract or expand) with global

46 change may be species-specific (Hallman \& Robinson, 2020; Radosavljevic \& Anderson, 2014), 
47 but research into how particular axes of climate change affect species with different life history

48 strategies, foraging guilds or habitat affinities provides promising insight that may apply to a

49 wider number of unstudied species (e.g., changing rainfall regimes - Brawn et al., 2017;

50 advances in spring phenology and breeding success - Sander et al., 2020).

A major gap in our understanding of how organisms may respond to changing

52 environments lies in movement behavior. In birds, research on migration routes and resource

53 tracking is well established in the Northern Hemisphere (Faaborg et al., 2010; Thorup et al.,

54 2017), although much less information is available for species that undergo seasonal movements

55 in the Southern Hemisphere. In the speciose Neotropics, $>50 \%$ of bird species are known to be

56 migratory, and an increase in knowledge of seasonal movements in remaining species could

57 augment this estimate this by up to $15 \%$ (Jahn et al., 2020; Rappole, 1995). Complexity is added

58 by varied seasonal movements that avian species undertake, including austral migrants (Jahn et

59 al., 2004, 2013), elevational migrants (Barçante et al., 2017; Hsiung et al., 2018), partial

60 migrants (Sekercioglu, 2010) and others with intratropical migration routes (e.g., Resplendent

61 Quetzal - Papeş et al., 2012; Three-wattled Bellbird - Powell \& Bjork, 1995) or extended daily

62 foraging routines (e.g., Oilbirds - Holland et al., 2009). Migratory bird species have been shown

63 to decline when the timing of annual life history events are mismatched with peaks in food

64 availability (Møller et al., 2008; Sander et al., 2020). On the other hand, multiple species of

65 Nearctic-Neotropical migrants are advancing dates of spring migration and breeding behavior in

66 response to warming spring temperatures (Dunn \& Møller, 2019; Pecl et al., 2017; Shipley et al.,

67 2020), offering support to the idea of "evolutionary rescue" such that existing variation within

68 annual programs may yield previously unknown adaptive potential (Helm et al., 2019). In this

69 review, we use literature on predictive bird distribution modelling to inform future work 
70 predicting the importance of dispersal limitation, biotic interactions and estimates of the

71 fundamental niche to understand climate-driven distributional shifts in birds and other taxa.

With specific attention on global temperature increases caused by climate change,

73 responses to shifting thermal environments will be varied and complex. Janzen's "seasonality

74 hypothesis" suggests that tropical organisms should be particularly sensitive to anomalies in

75 ambient conditions because their physiology is adapted to a relatively constant environment

76 (Janzen, 1967). This idea has since received much empirical support (Sheldon et al., 2018), and

77 highlighted the tropics for having a high concentration of thermal specialists that are vulnerable

78 to climate change (Mora et al., 2013). Tropical ectotherms (i.e., arthropod prey) tend to live near

79 the upper limits of their thermal optima and are therefore sensitive to even small temperature

80 increases (Deutsch et al., 2008). Endotherms (like birds), on the other hand, have the capacity to

81 tolerate ambient temperatures past their thermoneutral zone by raising metabolic activity to

82 produce evaporative cooling, but this increases energy and water demands at temperature

83 extremes (Gardner et al., 2011; Huey et al., 2012). Still, few studies have considered the

84 potential effects on presumably more thermally flexible endotherms due to changes in a more

85 thermally sensitive ectothermic prey base (Grady et al., 2019). An important consequence

86 stemming from Janzen's hypothesis is that lowland tropical species could be particularly affected

87 by novel conditions supplied by global change, resulting in broad-scale biotic attrition, except for

88 populations immediately adjacent to montane regions, which would have some access to upslope

89 thermal refugia (sensu Brodie et al., 2017; Colwell et al., 2008). At least some studies have

90 shown that tropical birds are unlikely to experience acute thermal limits to their distributions

91 (Londoño et al., 2015, 2017). While species may have a sufficient thermal margin to defend

92 against climate warming (Pollock et al., 2021), they will likely experience added 
93 thermoregulatory costs in response to shifting thermal regimes or movements (Londoño et al.,

94 2017). As the effects of increased temperature on populations can interact with critical ecological

95 and life-history parameters, temperature is expected to impact both current distributions and

96 species' responses to changing thermal environments.

97 Our review aims to synthesize theory, methods, and data sources widely used to predict

98 bird distributions under global change, and to highlight best-practices and opportunities for

99 innovation and refinement. Understanding where species occur and why some areas are occupied

100 but not others is essential for developing conservation and management plans. For most species,

101 knowledge of their distribution is limited to areas that have been surveyed. However, predictive

102 distribution modelling is important to identify areas for protection or management. Modelling

103 wide-ranging, unevenly distributed, cryptic, or difficult to survey species all present problems for

104 understanding factors driving occupancy. Understanding how behaviors and life history traits are

105 linked to patterns of occupancy requires focused investigation but are nevertheless critical layers

106 for informative distribution models. Here, we bring together the issues complicating predictive

107 distribution modelling to offer a solutions-oriented approach to habitat conservation under global

108 change.

109

\section{PREDICTIVE DISTRIBUTION MODEL THEORY}

111 The current dogma of species distribution modelling falls into two categories: 1) species

112 distribution models (hereafter SDMs) that comprise presence records and abiotic data, and 2)

113 ecological niche models (hereafter ENMs) that explicitly estimate the accessible environment

114 (Soberón \& Peterson, 2005). These approaches are meant to have high spatial accuracy but are

115 not meant to inform on cause-and-effect species-habitat relationships (Merow et al., 2013). 
116 Models can be based on different niche perspectives, which present unique frameworks for

117 estimating drivers of occupancy across a species' range. The Grinnellian class of niche reflects

118 abiotic drivers of site occupancy (Elton, 1927; Soberón, 2007; Wisz et al., 2013) and SDMs are

119 mainly built under the Grinnellian niche concept (Figure 1; Saupe et al., 2012). Coarse-scale

120 variables describing ecosystem characteristics are often the most relevant for predicting shifting

121 distributions across large spatial extents. In comparison, the Eltonian class of niche includes

122 estimates of biotic interactions and resource-consumer dynamics that are only quantifiable at

123 local scales (Figure 1; Elton, 1927; Soberón, 2007). Finally, the Hutchinsonian class of niche

124 reflects the functional role of a species, which is often estimated using functional traits and

125 species' habitat requirements based on functional traits (Rosado et al., 2016), and projects the

126 probability of site occupancy beyond study areas, including estimates of dispersal probabilities in

127 ENMs (Figure 1). A species' ability to move beyond their current realized niche depends on the

128 relative importance of abiotic factors, biotic interactions, and dispersal probability that operate at

129 different spatial scales (Jankowski et al., 2013). 


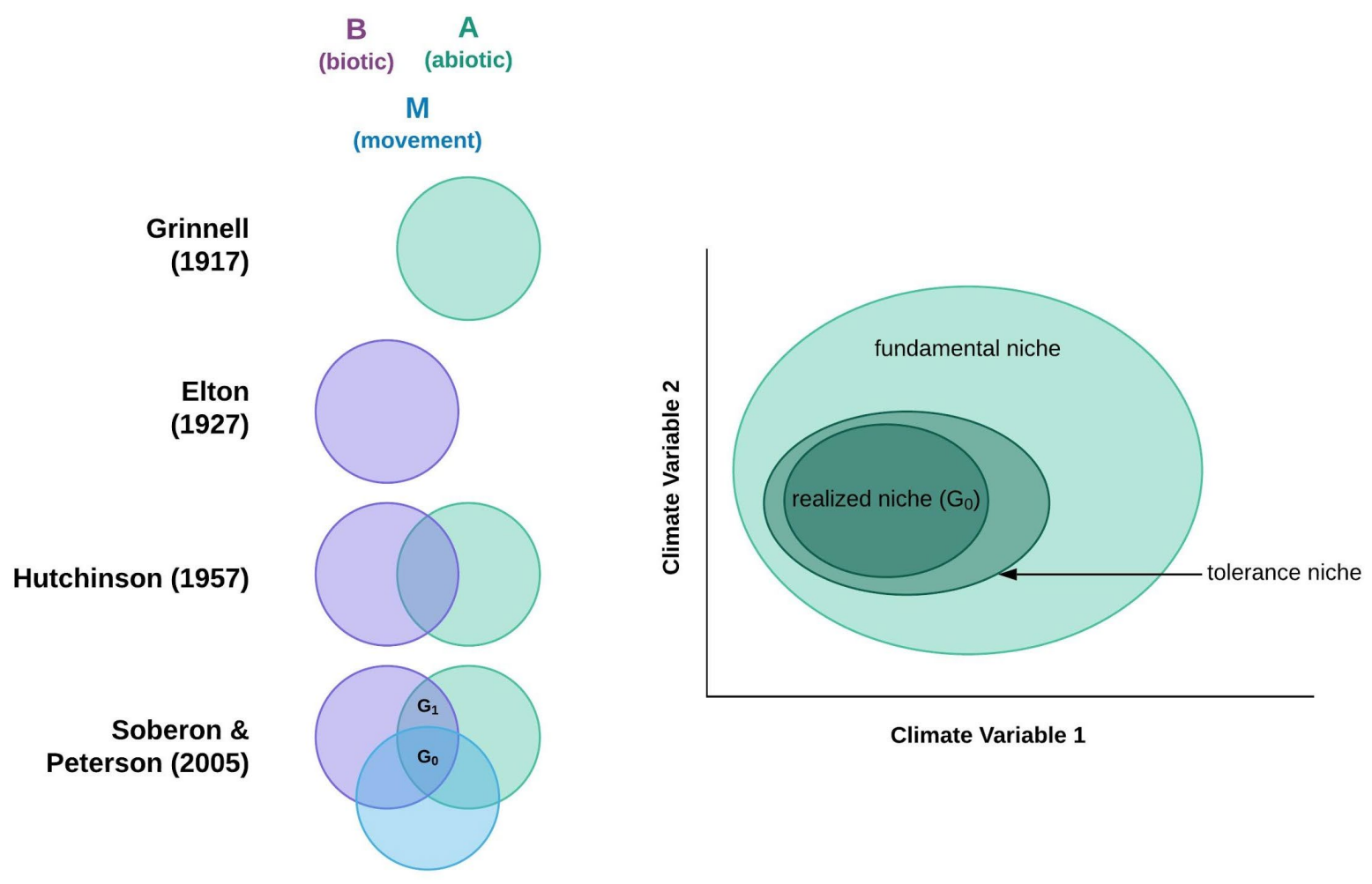

131 Figure 1. The "BAM" diagram. The relationship between "B" - biotic, "A" - abiotic, and "M" -

132 movement (also thought of as "access" and defined by dispersal ability) with respect to the

133 authors of various niche theories (left). The location of realized, tolerance, and fundamental

134 niche along the intersection of two hypothetical climate variables (right). Sax et al. (2013)

135 present an update to niche theory that considers three components of a species niche: 1) the

136 "realized niche", i.e., conditions within the native range, 2) the "fundamental niche" - conditions,

137 in which a species could thrive if it were introduced there, and 3) the "tolerance niche" -

138 conditions, in which individuals could survive, but likely unable to maintain populations over the

139 long-term. The fundamental niche is the set of appropriate abiotic conditions, and the realized

140 niche is a smaller area where both abiotic and biotic environments are suitable. Theoretically not

141 all of the realized niche could be accessible and so the potential range is yet smaller because it

142 reflects only the area that is suitable and also accessible to the species. Occurrence is not 
143 expected outside of the colored areas. The occupied area is represented by $\mathrm{G}_{0}$, and $\mathrm{G}_{1}$ reflects

144 appropriate conditions that have not or cannot be accessed by the species (as described by Saupe

145 et al., 2012).

Assessing occurrence or abundance along abiotic gradients is important for predicting

148 future range shifts under global change, as this relates directly to species' and populations'

149 responses to the environment. The gradual shifts in temperature and rainfall regimes can be

150 expected to align with changes in species responses, reflecting the shifts in optimal ambient

151 conditions and resulting in altered patterns of probability of occurrence or abundance. It is

152 important to note that ENM products are only able to predict the probability of site occupancy

153 within the range of abiotic conditions measured within current range boundaries, so will be

154 limited where climate change introduces novel climates (e.g., Williams et al., 2007).

155 Spatial ecology theory dictates that species respond to continuous environmental

156 gradients through gradual changes in abundance, as individuals experience shifting conditions

157 moving toward or away from environmental optima over space (Austin, 2005, 2007). However,

158 populations may also show thresholds in abiotic tolerances or in response to biotic factors that

159 change their response shape (e.g., creating asymmetric or skewed response functions; e.g.,

160 Oksanen \& Minchin, 2002). For example, the asymmetric abiotic stress (AASL) hypothesis

161 predicts a steeper decrease in a species' probability of occurrence toward the more stressful end

162 of a species' distribution, which has been supported in a number of vascular plant species

163 (Dvorský et al., 2017). Other threshold-type effects can result in asymmetric responses shown

164 across multiple species in communities (e.g., sharp ecotone boundaries, appearance of dominant

165 predators or competitors; Jankowski et al., 2013). Identifying response shapes is of practical 
interest to understand the impact of abiotic and biotic factors on occupancy. Comparisons across

167 species distinguish commonalities and differences in responses to gradients and can point to key

168 environmental variables driving patterns in community organization.

170 populations would be able to respond (in time and space) to changing conditions. Landscapes

171 can vary in ways that affect both the phenology of resources (time) or availability of habitat

172 (space); such variability can be tracked if conditions change at a pace that populations could

173 respond to. Examples of this include species adapted to annually ephemeral or temporally patchy

174 habitats such as wetlands and grasslands; species accustomed to such environments may have

175 dispersal strategies that predispose them to better track climate (e.g., Elaenia cristata - Ritter et

176 al., 2021). In other cases, habitat and resources are spatially patchily distributed, and the ability

177 of species to respond to changing conditions may be more taxon-specific for those that rely on

178 spatiotemporal heterogeneity that is naturally patchy. Examples of this include habitat specialists

179 in naturally patchy habitats such as Amazonian white sand habitats (e.g., Elaenia ruficeps -

180 Ritter et al., 2021).

181 Microclimate refugia allow animals to buffer themselves from acutely unfavorable

182 conditions. One example of this is through behavioral thermoregulation. Ambient temperature is

183 almost never constant in terrestrial environments - it varies by time, and by habitat, often at very

184 small scales (Scheffers et al., 2014, 2017). Biologists have long understood that mobile animals

185 exploit thermal heterogeneity to maintain optimal body temperature (Angilletta Jr \& Angilletta,

186 2009; Angilletta et al., 2009; Cowles \& Bogert, 1944; Porter et al., 1973; Stevenson, 1985). For

187 cold-adapted species in a heating world, this can be achieved by shifting activity times to cooler

188 periods of the year and day, and by moving to microhabitats that supply cooler microclimates. 
This capacity to compensate for unfavorable ambient temperature by behavioral

190 thermoregulation, known as the "Bogert Effect" (Huey et al., 2003), can at least partly mitigate

191 the harmful effects of climate warming (Huey et al., 2012). However, behavioral

192 thermoregulation is contingent on access to cooler areas and periods; animals already occurring

193 in the most buffered environments have limited options for escape when conditions change.

194 Furthermore, individuals could experience additional pressured from biotic interactions with 195 species moving into their habitat to thermoregulate (Huey et al., 2012). Dispersal limitation is one of three fundamental aspects of distribution theory (Figure 1).

197 Understanding barriers to distributions caused by dispersal limitation has been of great interest,

198 for example, in bird species unable to cross areas of unsuitable habitat, and has been studied both

199 experimentally (e.g., Moore et al., 2008) and theoretically (e.g., Ribas et al., 2012, 2018).

200 Selection pressures driving morphology, such as migratory compared to sedentary life histories, 201 may also play a role in physically limiting dispersal distance (Capurucho et al., 2020; Claramunt 202 et al., 2012; MacPherson et al., 2021; Sheard et al., 2020). Life history strategies also dictate the 203 demographic trends in dispersal; for example, in many species it is the inexperienced young that 204 disperse into new areas away from the territories of their parents (e.g., Florida Scrub Jay - Suh et 205 al., 2020). Dispersal limitation is thus a complex and difficult-to-quantify aspect of predictive 206 distribution modelling that is nevertheless fundamental for predicting the probability of range 207 shifts with global change. Coupling studies of distribution modelling with quantifiable measures 208 of dispersal capacity is an important next step toward making more informed predictions of 209 species responses to changing environments (Travis et al., 2013; Urban et al., 2013).

210 Generally, when confronted with climate change, species change in one of three ways: 1)

211 by going extinct, 2) surviving by shifting their geographic range, or 3) evolving in place. 
212 Evidence from the fossil record suggests all three responses are common (Graham et al., 1996;

213 Smith et al., 1995). The capacity to adapt or evolve in situ in response to climate change has

214 been relatively understudied (Parmesan \& Matthews, 2005). A recent meta-analysis of existing

215 studies of phenological and morphological adaptations to climate change concluded that

216 adaptation, while variable among taxa, will not likely work on a sufficient scale to mitigate the

217 worst effects of ongoing climate change, whereas phenological adaptation (e.g., timing of

218 reproduction or migration) may mitigate such effects, albeit imperfectly (Radchuk et al., 2019).

219 The expectation that species with short generation times should be able to survive by evolving in

220 place remains understudied. Advancing such research is hampered by the difficulty of

221 conducting experiments on large numbers of species at sufficient time scales needed to develop a

222 comprehensive framework (Holt et al., 2005; Pierson et al., 2015). Variability among taxa and

223 short time scales signal that selection pressure has yet to be strong enough to produce measurable

224 changes, though it appears that species shift their phenology faster where climate change velocity

225 is faster (Poloczanska et al., 2013). Among abiotic drivers, mainly precipitation changes (but

226 also temperature) seem to underlie adaptive responses to climate change (Caruso et al., 2017;

227 Siepielski et al., 2017). Dramatic changes in climate over the remainder of this century are

228 expected (Figure 2) with many species likely unable to survive in the areas they presently occupy

229 (Ceballos et al., 2015; Sax et al., 2013). Ramping up efforts that prioritize long-term monitoring

230 of populations will be important for informing predictions of the resiliency of species to climate

231 change. 

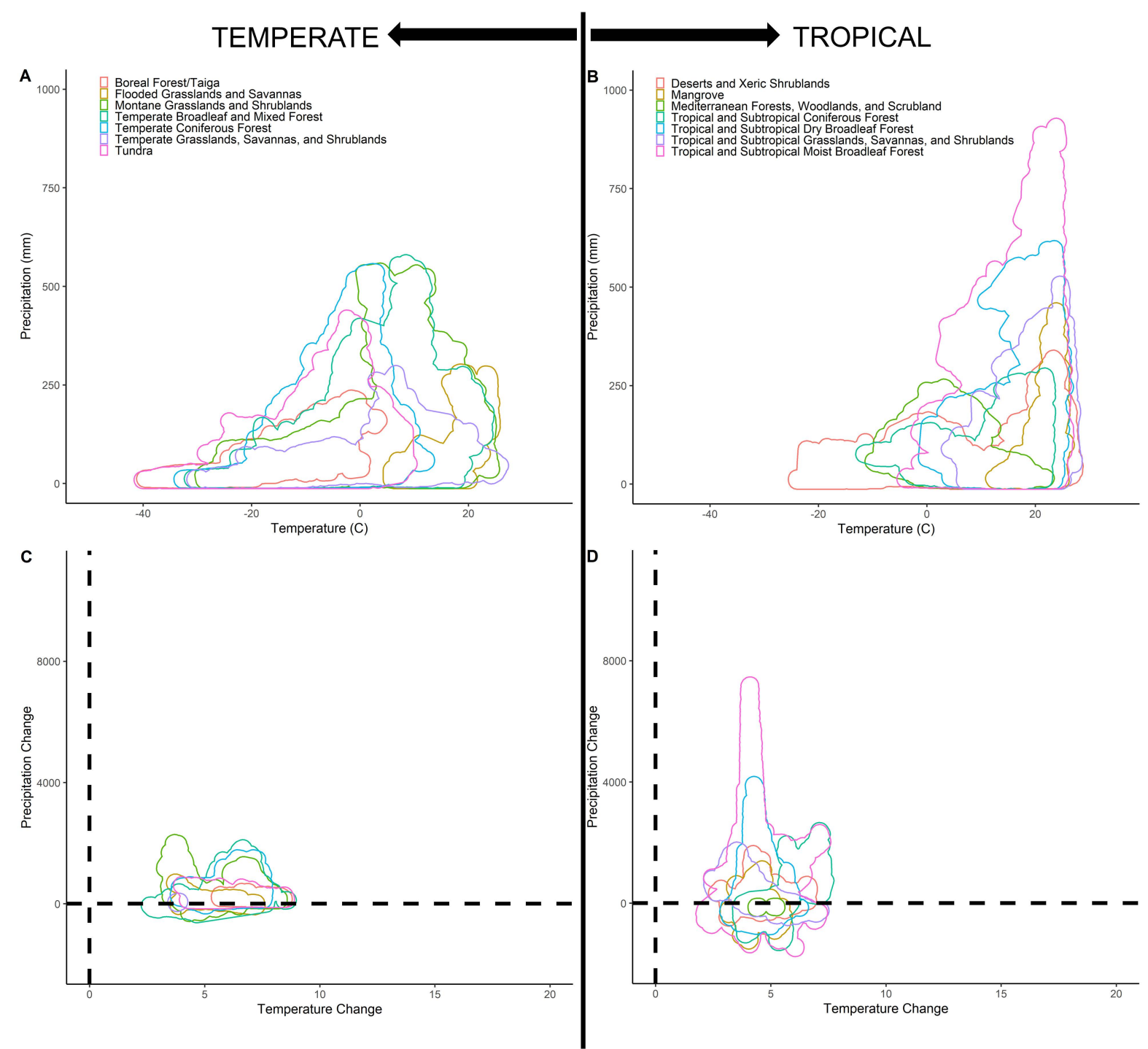

234 Figure 2. Current climate and predicted change in climate of global terrestrial biomes.

235 Climographs of (A) temperate and (B) tropical and subtropical global terrestrial biomes.

236 Projected changes in temperature and precipitation regimes for (C) temperate and (D) tropical

237 and subtropical global terrestrial biomes. While some areas are predicted to have increased or

238 decreased precipitation in the future, no areas are expected to have lower or stable temperatures.

239 Temperature increases are predicted to be higher in temperate biomes, while changes in

240 precipitation are greater for tropical biomes. Climographs built from The World Wildlife Fund

241 terrestrial ecoregions (https://www.worldwildlife.org/publications/terrestrial-ecoregions-of-the-

242 world) and current climate (2021-2040) from CanESM5 middle of the road scenario (SSP3-7.0) 
244 projected change is modeled as the difference between current climate (2021-2040, described

245 above) and future climate using the worst-case scenario (SSP4-6.0; 2081-2100) from CanESM5

246 global climate model data (Meinshausen et al., 2020). Species' presence, and thus biodiversity, is

247 highly influenced by biome type, which shifts from one form to another according to temperature

248 and rainfall regimes (Whittaker 1975). Projected changes in temperature and precipitation may

249 cause global terrestrial biomes to shift in space, but spatial gains and losses by different biomes

250 over time may not occur in synchrony with habitat needs to maintain biodiversity (Dorazio et al.,

251 2015). $\mathrm{R}$ code for producing this figure can be found at

252 https://github.com/mmacphe/Global_Change_Biomes.

255 small population paradigms. Population declines are driven by deterministic (demographic,

256 abiotic, and biotic) factors that cause reduction to small numbers (e.g., the Allee effect), and also

257 by stochastic factors, which dominate the extinction dynamics of small populations (Caughley,

258 1994; Morris \& Doak, 2002; Smith et al., 2021). The abiotic shifts in conditions due to climate

259 change and the resulting shifts in species distributions play a role in both types of population

260 dynamics. Shifting distributions can cause temporary or permanent reductions in habitat area

261 (Thomas et al., 2006; van Rees \& Reed, 2018), lowering carrying capacity and driving

262 population declines at local or regional scales, or reducing connectivity and creating isolated

263 subpopulations that are more susceptible to small-population dynamics (Anderson et al., 2009).

264 The degree to which changing distributions result in commonly observed conservation impacts

265 depends on a diversity of species traits including habitat preference and associations, phenotypic 
plasticity, and current range and population size (Jiguet et al., 2007; Visser, 2008). Notably,

267 research based solely on changes in distributions tends to predict widespread extinctions due to

268 the aforementioned mechanisms, but plasticity, dispersal, and adaptation appear to have been key

269 for many species' resilience to past and current climate change (Moritz \& Agudo, 2013). For

270 example, the Galapagos finches are a well-known example of phenotypic plasticity in bill

271 morphology in response to environmental change (Grant \& Grant, 2020; Grant \& Weiner, 2017;

272 Weiner, 1994).

\section{OCCURRENCE DATA FOR PREDICTIVE DISTRIBUTION MODELLING}

275 Occurrence data through time is the foundation for understanding species responses to global

276 change. To assess whether a change in distribution has occurred or will occur, researchers

277 require historical records to establish a baseline for comparison, followed by surveys at one or

278 more subsequent time points. Although birds are among the best studied animals, early baseline

279 inventories are still rare, and often consist of field notes (Reznick et al., 1994), which present

280 challenges particularly in reconstructing past abundances (Shaffer et al., 1998). Alternatively,

281 museum records are among the best sources of historical occurrence data, though they primarily

282 supply presence/absence data only (Shaffer et al., 1998).

In contrast to sparse information from the past, modern ornithologists benefit from

284 technological advances that offer unprecedented information on bird occurrence. As birds are

285 such mobile organisms, these include devices that can track individuals beyond specific field

286 research sites (satellite imagery - Borowicz et al., 2018; sophisticated automated biodiversity

287 data collection - Kitzes \& Schricker, 2019; for birds within appropriate size ranges - McKinnon

288 \& Love, 2018; and online citizen science efforts - Sullivan et al., 2009, 2014). They improve our 
understanding of avian ecology by identifying previously unknown species-habitat relationships

290 (Jirinec et al., 2016), migratory routes (Jahn et al., 2016, 2021; Stanley et al., 2012, 2015),

291 foraging areas and behaviors (including accessing microhabitat refuges - Wolfson et al., 2020),

292 and wintering distributions (Renfrew et al., 2013). These advances facilitate discovery of species

293 responses to global change by revealing locations outside of direct observation. Aside from

294 emerging technologies, simpler bird monitoring approaches implemented in the past at large

295 scales have amassed rich longitudinal data (e.g., breeding bird surveys and regional atlases), and

296 band recoveries across the globe continue to supply information on bird population trends and

297 distributions (MacPherson et al., in prep).

A major challenge for predictive models is rarity or sparseness of point occurrence data.

299 Even with many potential sources of occurrence data, knowledge of bird distributions still varies

300 greatly by species, habitat, and geography. For example, rare, nocturnal, and/or secretive species

301 and those in remote areas are difficult to detect and model accurately (MacKenzie et al., 2005;

302 Stralberg et al., 2015). Rarity is a common characteristic of species in diverse tropical

303 communities and remains a major challenge for constructing species distribution and

304 environmental niche models for tropical species. Still, there are approaches to modelling rare

305 species, for example, using Bayesian network analysis (Hamilton et al., 2015) or “ensemble

306 small models" (ESMs; Breiner et al., 2015; see "Analytical Methods” section, below).

307 Decisions about which type of occurrence data is best for predicting distributions under

308 global change varies based on the trade-off between addressing processes affecting the core

309 distribution versus a more holistic understanding that includes unique responses at range

310 boundaries, during different life history activities, or between different sex and age classes.

311 Understanding of distributions could be improved by increasing the number of studies examining 
312 range edges, and at finer temporal resolutions; "snapshots" in time do not provide a complete

313 picture of spatial resource requirements for individuals or populations. Passive acoustic

314 monitoring and long-term studies remain promising approaches for capturing relative abundance

315 data to estimate population dynamics with respect to global change (Pérez-Granados et al., 2019;

316 Pérez-Granados \& Schuchmann, 2020; Sugai et al., 2020). Trait databases are gaining

317 momentum as sources of functional diversity to test hypotheses under the Hutchinsonian niche

318 concept (Gallagher et al., 2020; Leclerc et al., 2020; Matuoka et al., 2020). In particular,

319 exploring how functional roles of species change across abiotic gradients can dramatically

320 improve our understanding of abiotic tolerances to more accurately predict range dynamics. For

321 example, bill size has been shown to be important for thermoregulation in birds (e.g., Danner \&

322 Greenberg, 2015) and a study of functional trait structure along a tropical elevational gradient in

323 Malaysian Borneo linked larger bills in low elevation communities with thermal tolerance

324 (Boyce et al., 2019). Current shortfalls in avian occurrence data (summarized by Lees et al.,

325 2020) require an integrated approach to predicting bird distributions with global change.

326 Although most efforts to collect occurrence data are from small spatial areas (e.g., from

327 individual field research sites) and coarse resolutions (Table 1), even incomplete general natural

328 history knowledge gained across spatial and temporal resolutions remains key to identifying

329 important explanatory variables responsible for supporting site occupancy now and into the

330 future.

332 Table 1. Geospatial context of common occurrence data sources for birds and explanatory

333 variables. Most occurrence data and explanatory variable data layers are of coarse spatial and

334 temporal resolution, making them useful for testing hypotheses under the Grinellian class of 
niche. Occurrence data sources with fine spatial and temporal resolution are not as common and

avian occurrence data see MacPherson et al. (in prep).

\begin{tabular}{|c|c|c|}
\hline Geospatial data qualities & Examples of occurrence data sources & Examples of explanatory variables \\
\hline $\begin{array}{l}\text { Large spatial area, coarse } \\
\text { spatial and/or temporal } \\
\text { resolution }\end{array}$ & $\begin{array}{l}\text { - Remote sensing assets (satellite } \\
\text { imagery, aerial imagery etc.) } \\
\text { - Automated radiotelemetry } \\
\text { - Geolocators } \\
\text { - eBird } \\
\text { - Stable hydrogen isotopes } \\
\text { - Genetic data }\end{array}$ & $\begin{array}{l}\text {-Long-term averages in stable climates } \\
\text { (e.g., WorldClim) } \\
\text {-Land cover (e.g., MODIS, GlobCover, } \\
\text { SPOT) } \\
\text { •Phenology and vegetation indices (e.g., } \\
\text { MODIS, Landsat) } \\
\text { •Climate record (e.g., NCDC, ClimateNA, } \\
\text { ClimateSA) } \\
\text {-Atmospheric weather reanalyses (e.g., } \\
\text { ERA, GPM, TRMM, NCEP) }\end{array}$ \\
\hline $\begin{array}{l}\text { Small spatial area, coarse } \\
\text { spatial and/or temporal } \\
\text { resolution }\end{array}$ & $\begin{array}{l}\text { - Citizen science (e.g., Breeding Bird } \\
\text { Surveys, Christmas Bird Counts) } \\
\text { - Natural history collections } \\
\text { - Field notes } \\
\text { - Point count surveys } \\
\text {-Passive acoustic monitoring } \\
\text { - Long-term datasets } \\
\text { - Bird banding data }\end{array}$ & \\
\hline $\begin{array}{l}\text { Large spatial area, fine spatial } \\
\text { and/or temporal resolution }\end{array}$ & $\cdot$ GPS tags & $\begin{array}{l}\text {-Digital elevation models (e.g., ASTER) } \\
\text { - Vegetation indices (e.g., SPOT) }\end{array}$ \\
\hline $\begin{array}{l}\text { Small spatial area, fine spatial } \\
\text { and/or temporal resolution }\end{array}$ & $\cdot$ VHF radio-tags & $\begin{array}{l}\text {-Personal weather data loggers } \\
\text {-Weather station data }\end{array}$ \\
\hline
\end{tabular}

SELECTING APPROPRIATE EXPLANATORY VARIABLES

343 Predicting distributions into the future relies on accurate assessments of current life history

344 requirements. In this section, we synthesize the spatial and temporal resolution of explanatory

345 variables commonly used to match distributions with habitat and resource needs. Producing

346 sound predictive models requires suitable proxies for resource or habitat needs that are

347 ecologically relevant (e.g., Burns et al., 2020; Randin et al., 2020). To scale up to entire

348 distributions, there must be an underlying knowledge of a species' life history that effectively 
links the lives of individuals to the explanatory variable (or proxy variable) associated with site occupancy. Predicting distributions into a future where the distributions of food webs will shift

351 requires a breadth in knowledge of life history information to predict the probability of species

352 ranges shifting individually or with their entire biotic community. This task is complicated by the

353 potentially differing needs for each life history stage or demographic, which is often the case for

354 birds (e.g., habitat requirements may differ between fledglings and adults). While the main

355 considerations are the spatial and temporal resolutions of explanatory variables, biotic

356 interactions can also play a critical role, and may need to be considered on a species-specific

357 basis.

SPATIAL RESOLUTION OF EXPLANATORY VARIABLES

360 Selecting the correct spatial resolution of explanatory variables is key to producing the most

361 accurate assessments of range shifts under global change. Passively remotely sensed spatial

362 products (e.g., NDVI and BIOCLIM variables) can be proxies for features of the environment

363 being used by individuals. Active remote sensing systems, for example light detection and

364 ranging (LiDAR) has also been used to predict occupancy by light-demanding versus shade-

365 tolerant plant species (Wüest et al., 2020). LiDAR can also offer direct measurements of

366 structural features of habitat (e.g., vertical distribution of forest canopy elements and foliage

367 density) useful in predicting species occupancy (e.g., Goetz et al., 2010). Remotely sensed

368 variables are thought to reflect a contingency of resources assuming the data product conveys

369 mutual information on a shared spatiotemporal scale with the amount of food resources (Riotte-

370 Lambert \& Matthiopoulos, 2020). There are some satisfying interpretations of the ecological

371 relevance of these remotely sensed products (see Bridge et al., 2016 (EVI); Renfrew et al., 2013 
372 (NDVI); Tøttrup et al., 2012 (drought)), although the typical purpose of using these large scale

373 variables is for spatial accuracy and not causal relationships, in that remotely sensed variables

374 generally serve as proxies for features of the environment used by individuals.

375 Nevertheless, many remotely sensed abiotic products do intend to reflect a direct habitat

376 resource or type. Habitat characteristics (i.e., land cover) are most often identified with remotely

377 sensed data, which depending on the sensor, can have a variety of resolutions. Medium-high

378 spatial resolutions $(\leq 30 \mathrm{~m}$, e.g., Landsat, Sentinel) are useful to pair with more precise

379 occurrence data (e.g., GPS tags, point counts; Shirley et al., 2013), whereas low spatial

380 resolution (e.g., MODIS) can be useful for occurrence data such as geolocators or weather radar

381 (Heim et al., 2020). The temporal resolution of remotely sensed data is a limitation, especially

382 when modelling the dynamic nature of migratory birds and habitat changes (MacPherson et al.,

383 2018; Roslin et al., 2021). The limitations in remotely sensed spatio-temporal resolution should

384 not be a deterrent in SDMs, however, because the information gained is not possible with other

385 data sources (He et al., 2015; Randin et al., 2020). Still, applied interpretations when spatial

386 and/or temporal resolutions do not match should be made with caution.

\section{TEMPORAL RESOLUTION OF EXPLANATORY VARIABLES}

389 The temporal predictability of resources is important for predicting future distributions because

390 annual life history strategies are dependent upon correctly timing life cycle events with required

391 resources. For example, it is widely held that birds breeding at high latitudes must correctly time

392 the hatching of young with annual insect emergence to maximize fledging success, and early

393 arrival to breeding grounds may enhance reproductive success (Alerstam, 2011; Kokko et al.,

394 2006; Nilsson et al., 2013; Smith \& Moore, 2005). Predictive distribution models are expected to 
be the most accurate when species-habitat correlations are assessed using occurrence and

396 environmental data gathered from the same time-period. However, the temporal resolution of

397 occurrence data is much finer than that at which environmental data is typically collected; this

398 can create a mismatch that limits the questions that can be answered using current approaches.

399 The habitat requirements for fulfilling life history needs may vary depending upon the particular

400 life history event (i.e., mate acquisition, rearing young, molting, migrating, etc.) and the species

401 life history strategy. Life history strategies vary in birds from those that have evolved to rely on

402 consistent resource availability (e.g., in the case of dietary or habitat specialists that cannot live

403 outside of narrow environmental conditions), to periodic resource abundance (e.g., seasonal,

404 annual, inter-annual weather patterns that drive migratory or irruptive population movements), or

405 unreliable resource availability (e.g., in nomadic taxa), and it is important to match locality data

406 in time to environmental data for accurate species-habitat assessment.

407 The temporal resolutions for widely used climate data varies, with trade-offs between

408 temporal and spatial resolution in addition to the state of products limiting the types of

409 distribution questions that can be informed by them (Table 1). Here, we demonstrate this point

410 by explaining temperature and rainfall data sources because these are the two most widely used

411 and generally important environmental factors in species distribution modelling (Bradie \&

412 Leung, 2017). The finest spatial and temporal resolution of environmental data is typically from

413 weather station data from the nearest station to the research site (e.g., from

414 https://www.wunderground.com/history) or by collecting weather data alongside occurrence data

415 using data loggers available from various manufacturers (e.g., Meter, Truebner). The ERA5-

416 Land dataset provides fine scale (hourly) temperature and precipitation data, but at a $9 \mathrm{~km}$ spatial

417 resolution from January 1981 to present 
419 Centers for Environmental Prediction (NCEP) provides global temperature and precipitation data

420 (four-times daily) data at a $0.25 \times 0.25$ degree grid resolution from 1948-present

421 (https://psl.noaa.gov/data/gridded/data.ncep.reanalysis.surface.html). WorldClim is a commonly

422 used source of environmental data and the current version (2.1) provides global monthly values

423 of min and max temperature, and precipitation averaged from 1970-2000 (Fick \& Hijmans,

424 2017). Historical monthly min and max temperature, and total precipitation data used for

425 hindcasting are averaged by decade from 1960-2018 (Fick \& Hijmans, 2017; Harris et al., 2014).

426 BioClim data are 19 quarterly estimates derived from WorldClim monthly temperature and

427 rainfall values that are thought to be more biologically meaningful than raw temperature or

428 rainfall data (Busby, 1991). Bioclimatic variables have been averaged for the years 1970-2000 to

429 generate monthly estimates (Fick \& Hijmans, 2017). Despite being powerful tools for assessing

430 macroclimate associations, caution should be used when using the most accessible climate

431 products to assess the probability of future range locations.

To build robust predictive models, it is necessary to match the spatial and temporal

433 resolution of the occurrence data with that of the habitat characteristics. The temporal resolution

434 of remotely sensed data is a limitation, especially when modelling the dynamic nature of

435 migratory birds where dynamic seasonal habitat changes drive short-term habitat quality (e.g.,

436 seasonally flooded mudflat habitat for migrating shorebirds; Twedt, 2013). Google Earth Engine

437 (a java script based platform where one can write their own code to integrate many satellite

438 products and independently calculate indices such as NDVI) is a flexible tool that can facilitate

439 identifying the correct temporal resolution of land cover data to robustly test explanatory power

440 of land cover variables. Examples of data sets in Google Earth Engine include vegetation indices 
441 (Landsat, 2 weeks temporal resolution), products for creating land cover classifications (SPOT,

$442 \sim 1$ month), and land cover datasets (e.g., GlobCover, Cropland Data Layers, National Land

443 Cover Database; Table 1).

\section{BIOTIC FACTORS}

446 Modeling future range shifts in response to global change rarely considers biotic factors. This

447 omission is the main reason why an assumption of SDMs - that the species is at equilibrium with

448 their environment - is rarely, if ever, met (Pearson \& Dawson, 2003). If this assumption were

449 true, a species' realized and fundamental niche would completely overlap as long as the species

450 could access all available suitable niche space (Figure 1). Consideration of biotic factors has the

451 potential to significantly enrich the field of predictive distribution modelling with more accurate

452 forecasts, and here we synthesize leading research contributing to this end at both the

453 intraspecific and interspecific level.

454 There remains a gap in statistical approaches that account for biotic interactions in

455 forecasting species distributions. It is thought that biotic interactions vary along abiotic gradients

456 such that biotic interactions can either enhance or reduce predicted ranges (Louthan et al., 2015).

457 However, because capturing this information requires both high spatial and high temporal

458 accuracy across all abiotic scenarios within the realized niche, there are few examples to draw

459 from. One promising approach to including biotic interactions in predictive spatial modelling is

460 the development of causal models that estimate the influence of interspecific competition using

461 co-occurrence data (e.g., Staniczenko et al., 2017). The scope and strength of biotic factors may

462 be correlated with abiotic pressures (Louthan et al., 2015), and may differ depending upon which

463 range edge is being considered. For example, much work has been done in the bird literature to 
464 improve our understanding of species-habitat relationships through the study of hybrid zones,

465 which typically occupy only one part of a species range (e.g., Taylor et al., 2014). Quantification

466 of biotic factors, like the ones described here, requires targeted species-specific research to test

467 hypotheses within the Eltonian and Hutchinsonian classes of niche. This research is mainly done

468 within small spatial extents and without consideration of temporal or spatial resolution (e.g., co-

469 occurrence records from different time periods or datasets with different spatial resolutions -

470 Atauchi et al., 2018; Palacio \& Girini, 2018; see also König et al., 2021), but some research has

471 been done at large spatial extents and coarse resolutions (e.g., Acorn Woodpecker occurrence

472 with Colombian Oaks in the Northern Andes - Freeman \& Mason, 2015).

474 intraspecific biotic factors that shape current distributions. Intraspecific competition can drive

475 density-dependent range shifts in migratory species such that interannual selection of wintering

476 locations are dependent on group size and food availability (Corre et al., 2020). Dispersal

477 limitation can contribute to inadequacies in recruitment to new or population sink sites, limiting

478 population recovery or range shifts despite available habitat (Palma et al., 2020). The ability to

479 update behaviors when circumstances change (behavioral flexibility) may be key for driving

480 range shifts or expansions under global change (Blaisdell et al., 2020). Further, bird species

481 capable of behavioral innovation (a.k.a. plasticity) often have lower risk of extinction, as they are

482 better able to adapt to changing ecosystems and habitat destruction (Ducatez et al., 2020; Reed et

483 al., 1999). Additionally, metapopulation dynamics can affect the introgression of adaptive traits

484 such that maladaptive traits restrict range shifts under global change (e.g., Garcia-R \& Matzke,

485 2021; Lavretsky et al., 2020). Each of these examples are implicitly expected to vary across 
abiotic gradients, highlighting the importance of assessing the probability of site occupancy beyond the core of a species distribution. distributions because this requires a breadth of natural history knowledge beyond that of the species in question. However, interspecific biotic factors are thought to have strong influences on the probability of site occupancy. Species may be excluded through predator/prey dynamics where patches of habitat occupied by a species' predator may be less likely to be occupied by the species being studied (Léandri-Breton \& Bêty, 2020). Interspecific competition can also exclude species and is often assessed using co-occurrence data (Elsen et al., 2017; Freeman et al., 2016, 2019; Jankowski et al., 2010). Commensalisms, where one organism benefits from the presence of another organism and the other unaffected, can also facilitate site occupancy (Aitken \&

497 Martin, 2007). Including data on the presence of predators, competitors, and commensalisms in 498 SDMs can be a useful addition to improving models (Jankowski et al., 2013). Alternatively, the spatial overlap with other taxa may have little influence if the focal species exhibits behavioral avoidance (e.g., via interference competition - Jaeger, 1970; or predator-prey dynamics - Lukas et al., 2021) or the spatio-temporal scope of data are not aligned. researchers are mindful when selecting environmental data suited to answer questions about their

505 occurrence data (i.e., using ecologically relevant environmental and climate data across

506 biologically relevant space and timescales), a challenge remains in combining and contrasting

507 the Grinnellian class of niche (e.g., climate variables) against other niche classes that require

508 finer temporal and spatial data (e.g., density of interacting species). This problem can further 
bioRxiv preprint doi: https://doi.org/10.1101/2021.05.26.445867; this version posted May 27, 2021. The copyright holder for this preprint (which was not certified by peer review) is the author/funder, who has granted bioRxiv a license to display the preprint in perpetuity. It is made available under aCC-BY-NC 4.0 International license.

complicate predictive models if site occupancy is dependent on time-lags, as is the case in some

510 migratory species (Bridge et al., 2016), and is explored further in the following "Analytical

511 Methods" section.

513 ANALYTICAL METHODS

514 Predictive models of species distributions can be divided into correlative versus mechanistic

515 approaches (Figure 3). Correlative models elucidate relationships between species occurrence

516 and spatially explicit explanatory variables and can be viewed as hypothesis generating tools.

517 Data to parameterize correlative models are more readily available, making them the dominant

518 source of predictive distribution models. Mechanistic models are hypothesis-testing tools that

519 incorporate physiological tolerance to predict where species will be capable of persisting within

520 their physiological limits (Guisan \& Zimmermann, 2000).

Distribution - The area in geographic space over which a taxon is expected to occur.

Occupancy - The probability with which a taxon is expected to occur (or be detected) in a given area.

Rarity - A relative low probability of occurrence or restricted distribution.

Background points - Typically, randomized locations used to characterize the values of environmental parameters within a study area where known occurrences have not occurred.

Pseudoabsence - Background points that are used specifically in presence-only modeling to simulate absences or nondetections

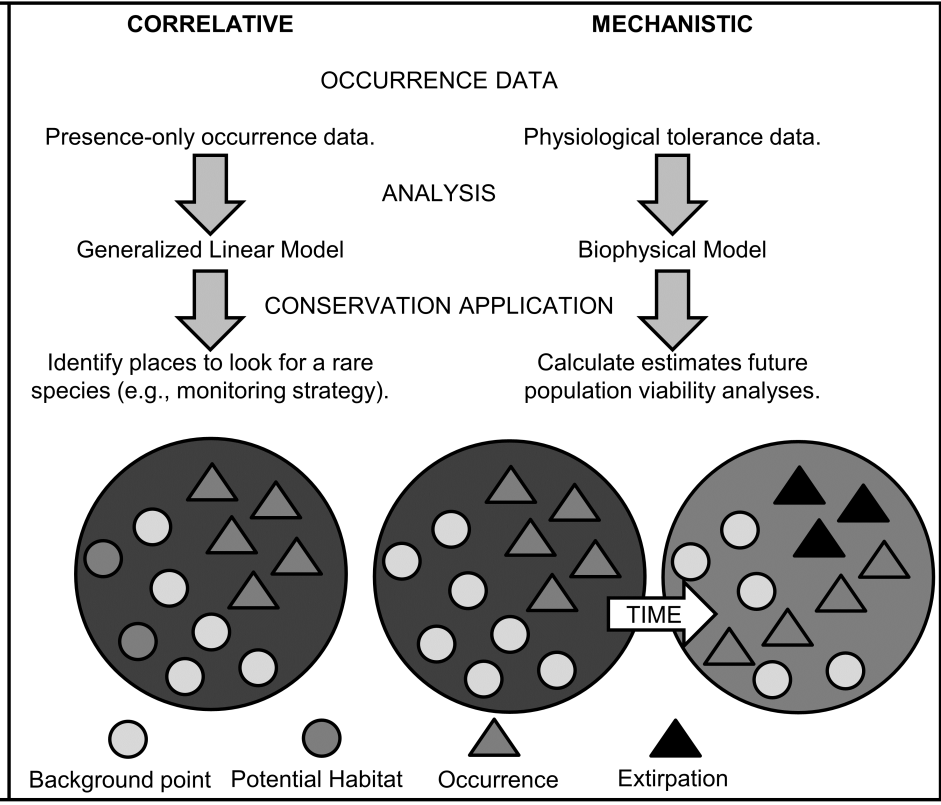

522 describing distribution model data. Right: Parallel workflows for example correlative versus

524 mechanistic predictive modelling. 
527 us better understand species and their sensitivities to global change. MAXENT is one of the most

528 popular SDM approaches, widely used for its ability to use presence-only datasets where true

529 absence or non-detection data are typically hard to find (Elith \& Leathwick, 2007; Merow et al.,

530 2013). MAXENT has been useful for modelling distributions of rare or cryptic species due to its

531 apparent high performance with small or incomplete datasets (Aubry et al., 2017; Pearson et al.,

532 2007; Phillips et al., 2006; Wisz et al., 2008; but see also Marini et al., 2009). Boosted regression

533 trees (BRTs) are one of many machine learning techniques well-suited to modelling complex

534 ecological data because they can handle different types of predictor variables, fit complex

535 nonlinear relationships, accommodate missing data and automatically handle interaction effects

536 between predictors (Elith et al., 2008; Graham et al., 2008). BRTs have been used to predict bird

537 distributions using occurrence data for waterfowl (Barker et al., 2014), shorebirds (Dalgarno et

538 al., 2017), seabirds (Oppel et al., 2012), and owls (Domahidi et al., 2019). Hierarchical Bayesian

539 models can integrate various data types (e.g., presence-absence, presence-only, count data) to

540 create reliable spatio-temporal distribution models (Hefley \& Hooten, 2015). Using continuous

541 spatial predictor variables such as land cover, the abundance and distribution of species can be

542 predicted over a continuous latent surface (Chakraborty et al., 2010), which has been useful with

543 waterfowl aerial survey data (Herbert et al., 2018, 2021). Generalized linear models (GLMs) and

544 generalized additive models (GAMs) can be employed to understand distributions across

545 multiple environmental conditions and also conceptualize patterns in distributions of abundances

546 across environmental gradients (Augustin et al., 1996; Smith \& Edwards, 2021). GAMs can be

547 used to estimate species' response curves with smoothing functions, which offer more flexibility 
to capture complex shapes not possible with GLMs (e.g., Maggini et al., 2011). One drawback to

549 GAMs, however, is that evaluation of response shapes (e.g., optima, skewness) is done through

550 visual inspection rather than statistically. Huisman-Olff-Fresco (HOF) models are used to predict

551 occupancy along abiotic gradients and are particularly useful in evaluating alternative shapes of

552 species responses to gradients, for example, if changes in abundance do not exhibit the widely

553 assumed symmetric Gaussian functions, but instead show asymmetric, threshold-like changes in

554 occupancy over space. HOF response curves can be used to highlight distinct distribution

555 patterns such as species replacements, allowing inference of potential biotic interactions that are

556 otherwise difficult to measure (Jansen \& Oksanen, 2013). The choice of predictive SDM

557 technique and quality of SDM product are based predominantly on the type of occurrence data

558 available and secondarily on spatiotemporal matching of explanatory variables.

560 presence. More specifically, biophysical models predict areas where physico-chemical processes

561 meet life history needs (Kearney, 2006; Michael Kearney \& Porter, 2009). For example, a

562 biophysical model for the endangered Night Parrot (Pezoporus occidentalis) shows how air

563 temperature increases of $3{ }^{\circ} \mathrm{C}$ would lead to lethal levels of dehydration (Kearney et al., 2016).

564 Bayesian networks (BNs) are another type of mechanistic model that go beyond species-habitat

565 correlations by also considering processes that influence occupancy across space and time (i.e.,

566 site access and selection - Jones, 2001). Originally employed to model human judgement (Pearl,

567 1985), BNs have only recently been adapted for predictive SDMs (MacPherson et al., 2018;

568 Staniczenko et al., 2017). Mechanistic models are informed by causal relationships based on

569 empirical research or expert knowledge, the latter of which are referred to as belief networks

570 (Drew \& Collazo, 2014; MacPherson et al., 2018). Mechanistic models enable the identification 
571 of the most important variables driving distribution patterns through mapping the fundamental

572 niche, which is helpful to inform conservation and management decisions when circumstances

573 change.

574 Conservation plans rely on SDMs for future species distributions, despite the small, but 575 growing, body of literature on ways to incorporate climate change into conservation planning

576 (Jones \& Cheung, 2015; Loyola et al., 2013; Nakao et al., 2013; Terribile et al., 2012). Using

577 correlative predictive models is likely to overestimate range shifts and extinction risk due to the

578 violations of common assumptions in correlative distribution modeling. For example, SDMs tend

579 to violate the assumption that the individual species is currently at equilibrium within its

580 environment (Early \& Sax, 2014; Sax et al., 2013) and do not take into account species

581 interactions (Pearson \& Dawson, 2003). Despite these criticisms, SDMs remain the "best"

582 widely accessible approach currently in use for identifying potential future habitat-area (Tingley

583 et al., 2014).

Ensemble modeling strategies, in which the predictions of multiple approaches are

585 combined or used simultaneously, are often suggested to better encompass the range of

586 uncertainty in prediction (Araújo \& New, 2007). This method accounts for the fact that model

587 choice is often the greatest source of quantifiable uncertainty in species distribution modeling,

588 and reduces sources of bias from the use of a single algorithm (Dormann et al., 2008; Jarnevich

589 et al., 2017). Implementing ensembles of five or more of the algorithms and approaches

590 described above has been greatly facilitated by software packages like BIOMOD (Thuiller et al.,

591 2009) and VisTrails SAHM (Morisette et al., 2013), which bring methods together into a single

592 analytical environment. Ensembles can be used to assess a range of potential projected outcomes,

593 forming a "bounding box" or "consensus" across algorithm predictions (Araújo \& New, 2007). 
594 Analysis with model ensembles typically involves scaling and averaging model outputs and,

595 often weighting these by some measurement of model performance such as "area under the

596 curve" score.

The ongoing "big data revolution" in many fields including ornithology (La Sorte et al., 2018) has increased use of artificial intelligence for data handling and analysis (Xia et al., 2020), especially in correlative distribution modeling. Machine learning algorithms like MAXENT

600 (Merow et al., 2013), random forests (Mi et al., 2017), neural networks (e.g., Manel et al., 1999),

601 deep learning (Benkendorf \& Hawkins, 2020) and boosted regression trees (Elith et al., 2006) are

602 now commonly applied SDMs, and are valued for prediction and interpolation. They are

603 excellent tools for insight into potential future shifts under global change (Elith, 2017).

\section{DISCUSSION}

606 Predicting where species will live in a warmer future is a central goal of modern ecology. This

607 effort has recast the basic research question of what limits distribution of species - why a species

608 lives here but not there - as an applied question. Species are already on the move in response to

609 recent decades of warming (and, depending on the region, predicted trends of reduced or

610 increased rainfall; Figure 2), supporting long-held theory that climate limits species' geographic

611 ranges (Tingley et al., 2009). However, the match between species' distributions and climatic

612 conditions is often weak; species vary considerably in their observed responses to recent climate

613 change. These observations indicate that we are still in the early stages of ecological forecasting.

614 In this research review, we have highlighted the theory underpinning how climate is related to

615 species' distributions and focused especially on the types of data sources and analytic approaches 
616 that are useful for predictive modeling of species' geographic responses to ongoing climate

617 change.

618 Here we briefly highlight three motivating questions to guide future research; the answers

619 to these questions are particularly likely to generate useful insights.

\section{1. Is dispersal a rate-limiting step in range expansions?}

622 The proximate driver of range shifts is dispersal; ranges expand when individuals move beyond

623 the existing range limit. Dispersal constraints are thus one obvious explanation for cases where

624 species' observed range shifts are failing to track changing climate. Birds have incredible

625 capacities for dispersal (e.g., Slager, 2020), making it tempting to gloss over a possible role for

626 dispersal constraints in avian range shifts, including unexplored topics such as site fidelity.

627 However, tropical species often show extreme limitations on dispersal, suggesting that longer-

628 distance range shifts (e.g., across latitudes) may be slow, particularly when landscapes are

629 patchy, or when species show high specialization to their associated habitats. In the temperate

630 zone, even some long-distance migrants may show incredible site fidelity to breeding (and

631 wintering) territories (Winger et al., 2019), which suggests the possibility that rapid range shifts

632 may be difficult to achieve. Lastly, dispersal may be possible but may introduce a new trade-off

633 with other components of the annual life cycle, such as migration. For example, the ability of

634 boreal breeding birds to take advantage of newly available forest habitat in the Arctic may be

635 constrained by a trade-off with ever-increasing migration distances. 
638 Ecological theory assumes that species are most abundant at the center or core of their range and

639 become progressively rarer towards their range limits (the "abundant-center hypothesis; Brown,

640 1984). However, empirical patterns of abundance often fail to fit these expectations. Whether the

641 abundant-center hypothesis generally holds or not is now a matter of debate (e.g., Dallas et al.,

642 2020), and the answer may have consequences for rates of species' range shifts. For example,

643 low abundances at range edges could lead to slower rates of range shifts than if abundance

644 distributions are more uniform across a core-to-limit transect through a species' geographic

645 range. This could be due to simple numeric effects - range shifts are easier when there are more

646 individuals at the range edge to start with - or to genetic effects. That is, low abundances (and

647 hence lower genetic diversity) could reduce local rates of adaptation at range edges, with gene

648 flow from the abundant range center swamping any effect of local adaptation at the range edge

649 that would facilitate range expansion when conditions change (Haldane, 1956; but see Kottler et

650 al., 2021). Studies on invasive species have the potential to improve our understanding of the

651 mechanisms that promote expansion from original range boundaries (e.g., the tolerance niche of

652 the Asian Openbill Bird - Lei \& Liu, 2021; and climate matching in the European Bee-eater -

653 Stiels et al., 2021).

\section{3. How does land use change interact with climate change?}

656 Like most of the range shift literature, we have focused in this review on predicting species'

657 responses to changes in climate per se. But species are shifting (or failing to shift) their ranges in

658 landscapes that, more often than not, are dominated by human activities. Studies that

659 simultaneously incorporate both land use and climate change as drivers of distributional change

660 are few in number but hold great promise for several reasons. First, land use change is an 
661 obvious driver of species' distributions; many species simply do not persist in landscapes with

662 extreme levels of human control. Second, appropriate habitat for most species in human-

663 dominated landscapes consists of habitat patches of varying sizes with varying levels of

664 connectivity (e.g., Neilan et al., 2019). This fact elevates the role of dispersal in determining

665 whether patches (and, scaled-up to a larger geographic scale, regions) are occupied by a given

666 species. Third, habitat change directly affects local-scale climate. Fragmented forests, for

667 example, average substantially warmer and drier than primary forests (Kapos, 1989), and "urban

668 heat islands" alter local temperatures that are known to affect bird distributions (in migrants -

669 Bonnet-Lebrun et al., 2020; and residents - Latimer \& Zuckerberg, 2021). Hence, land use

670 change can act as a multiplier of temperature effects on species.

673 predictions of extinctions. Some evidence suggests these dire predictions may be coming true.

674 For example, warming temperatures have led to local extinctions in mountaintop communities in

675 southeastern Peru as species shift their geographic ranges to track climate, a potential harbinger

676 of the possible extinction of high elevation tropical species (Feeley et al., 2012; Freeman et al.,

677 2018; Rehm \& Feeley, 2016). Yet species may be more resilient than models assume; for

678 example, genetic data indicate that many species were able to persist through dramatic climate

679 fluctuations in the Pleistocene (Bocalini et al., 2021; Song et al., 2020; Wogan et al., 2020).

\section{CONCLUSION}

682 Humans have already made Earth hotter than it has been since before the Pleistocene $(\sim 2$ million 683 years ago). This rapid change in Earth's climate has set species on the move and led to a plethora 
of scientific research aimed at predicting where species will live in the coming decades as warming continues. These predictions, though frequently made, are seldom tested. Without this crucial step of model validation, it is impossible to assess the usefulness of predictive models. Here, we have presented theory and highlighted a range of data sources and analytical approaches that can be used to predict species' geographic responses to climate change. Evergreater computational power, combined with increasingly large datasets of species occurrence and landscape covariates, permit the use of greater complexity in models. However, more complex does not necessarily equate to better. The litmus test for any predictive model is how

692 well it predicts reality. To this end, we advocate for an increasing focus on collecting empirical

693 data that matches the spatio-temporal resolution of occurrence data with environmental variables,

694 tests hypotheses beyond the Grinnellian class of niche, and directly evaluates model predictions

695 (e.g., using mechanistic SDMs or resurveys). For example, the long-term predictions from models whose predictions are not met over the short-term are unlikely to be helpful. Determining species' resiliency will depend on accurate estimates of the fundamental niche including which attributes make some species more vulnerable than others, which abiotic gradients are the most important to consider for the promotion of population persistence, and including biotic interactions in predictive, validated models. The ongoing pursuit of meaningful predictive distribution models under land use and climate change will be of great utility.

\section{ACKNOWLEDGEMENTS}

704 The authors declare that we have no sources of conflict of interest affecting the objectivity of the presented topic. This manuscript is the result of a synthesis on how ornithologists predict bird distributions under global change that was presented in a series of talks at the North American Ornithological Congress, 2020. We sincerely thank the organizers of this conference for their support throughout the COVID-19 pandemic. Thank you also to the participants of the Predicting Bird Distributions Under Global Change symposium, including William Lewis. This research was funded in part by a U.S. Geological Survey Northwest Climate Adaptation Science Center award G17AC000218 to C.B. van Rees. The manuscript was approved by the Director of the 
712 Louisiana State University Agricultural Center as manuscript number 2021-XXX-XXXX. The 713 authors would also like to thank (in alphabetical order by last name) Nicholas Mason, Subir 714 Shakya, Philip Stouffer, David Vander Pluym, and Brenna Wells who provided important

715 discussion of the topics presented in this manuscript during its development.

\section{LITERATURE CITED}

718 Aitken, K. E. H., \& Martin, K. (2007). The importance of excavators in hole-nesting communities: Ornithology, 148(2), 425-434. https://doi.org/10.1007/s10336-007-0166-9

Alerstam, T. (2011). Optimal bird migration revisited. Journal of Ornithology, 152(1), 5-23.

Anderson, B. j, Akçakaya, H. r, Araújo, M. b, Fordham, D. a, Martinez-Meyer, E., Thuiller, W., \& Brook, B. w. (2009). Dynamics of range margins for metapopulations under climate change. Proceedings of the Royal Society B: Biological Sciences, 276(1661), 1415-1420.

Angilletta Jr, M. J., \& Angilletta, M. J. (2009). Thermal adaptation: A theoretical and empirical synthesis.

Angilletta, M. J., Sears, M. W., \& Pringle, R. M. (2009). Spatial dynamics of nesting behavior: Lizards shift microhabitats to construct nests with beneficial thermal properties. Ecology, 90(10), 2933-

Araújo, M. B., \& New, M. (2007). Ensemble forecasting of species distributions. Trends in Ecology \& Evolution, 22(1), 42-47. https://doi.org/10.1016/j.tree.2006.09.010

734 Atauchi, P. J., Peterson, A. T., \& Flanagan, J. (2018). Species distribution models for Peruvian plantcutter improve with consideration of biotic interactions. Journal of Avian Biology, 49(3), jav-01617. https://doi.org/10.1111/jav.01617

Aubry, K. B., Raley, C. M., \& McKelvey, K. S. (2017). The importance of data quality for generating reliable distribution models for rare, elusive, and cryptic species. PLOS ONE, 12(6), e0179152. https://doi.org/10.1371/journal.pone.0179152 
Augustin, N. H., Mugglestone, M. A., \& Buckland, S. T. (1996). An autologistic model for the spatial distribution of wildlife. Journal of Applied Ecology, 33(2), 339-347. https://doi.org/10.2307/2404755

Austin, M. (2005). Vegetation and environment: Discontinuous and continuous. Vegetation Ecology, 5284.

Austin, M. (2007). Species distribution models and ecological theory: A critical assessment and some possible new approaches. Ecological Modelling, 200(1), 1-19. https://doi.org/10.1016/j.ecolmodel.2006.07.005

Barçante, L., Vale, M. M., \& Alves, M. A. S. (2017). Altitudinal migration by birds: A review of the literature and a comprehensive list of species. Journal of Field Ornithology, 88(4), 321-335. https://doi.org/10.1111/jofo.12234

Barker, N. K. S., Cumming, S. G., \& Darveau, M. (2014). Models to predict the distribution and abundance of breeding ducks in Canada. Avian Conservation and Ecology, 9(2), art7. https://doi.org/10.5751/ACE-00699-090207

Benkendorf, D. J., \& Hawkins, C. P. (2020). Effects of sample size and network depth on a deep learning approach to species distribution modeling. Ecological Informatics, 60, 101137. https://doi.org/10.1016/j.ecoinf.2020.101137

Blaisdell, A., Seitz, B., Rowney, C., Folsom, M., MacPherson, M., Deffner, D., \& Logan, C. (2020). Do the more flexible individuals rely more on causal cognition? Observation versus intervention in causal inference in great-tailed grackles. PsyArXiv. https://doi.org/10.31234/osf.io/z4p6s

Bocalini, F., Bolívar-Leguizamón, S. D., Silveira, L. F., \& Bravo, G. A. (2021). Comparative phylogeographic and demographic analyses reveal a congruent pattern of sister relationships between bird populations of the northern and south-central Atlantic Forest. Molecular Phylogenetics and Evolution, 154, 106973. https://doi.org/10.1016/j.ympev.2020.106973

Bonnet-Lebrun, A.-S., Manica, A., \& Rodrigues, A. S. L. (2020). Effects of urbanization on bird migration. Biological Conservation, 244, 108423. https://doi.org/10.1016/j.biocon.2020.108423 
Borowicz, A., McDowall, P., Youngflesh, C., Sayre-McCord, T., Clucas, G., Herman, R., Forrest, S., Rider, M., Schwaller, M., Hart, T., Jenouvrier, S., Polito, M. J., Singh, H., \& Lynch, H. J. (2018). Multi-modal survey of Adélie penguin mega-colonies reveals the Danger Islands as a seabird hotspot. Scientific Reports, 8(1), 3926. https://doi.org/10.1038/s41598-018-22313-w

Boyce, A. J., Shakya, S., Sheldon, F. H., Moyle, R. G., \& Martin, T. E. (2019). Biotic interactions are the dominant drivers of phylogenetic and functional structure in bird communities along a tropical elevational gradient. The Auk, 136(ukz054). https://doi.org/10.1093/auk/ukz054

Bradie, J., \& Leung, B. (2017). A quantitative synthesis of the importance of variables used in MaxEnt species distribution models. Journal of Biogeography, 44(6), 1344-1361. https://doi.org/10.1111/jbi.12894

Brawn, J. D., Benson, T. J., Stager, M., Sly, N. D., \& Tarwater, C. E. (2017). Impacts of changing rainfall regime on the demography of tropical birds. Nature Climate Change, 7(2), 133-136. https://doi.org/10.1038/nclimate3183

Breiner, F. T., Guisan, A., Bergamini, A., \& Nobis, M. P. (2015). Overcoming limitations of modelling rare species by using ensembles of small models. Methods in Ecology and Evolution, 6(10), 1210-1218. https://doi.org/10.1111/2041-210X.12403

Bridge, E. S., Ross, J. D., Contina, A. J., \& Kelly, J. F. (2016). Do molt-migrant songbirds optimize migration routes based on primary productivity? Behavioral Ecology, 27(3), 784-792. https://doi.org/10.1093/beheco/arv199

Brodie, J. F., Strimas-Mackey, M., Mohd-Azlan, J., Granados, A., Bernard, H., Giordano, A. J., \& Helmy, O. E. (2017). Lowland biotic attrition revisited: Body size and variation among climate change 'winners' and 'losers.' Proceedings of the Royal Society B: Biological Sciences, 284(1847), 20162335. https://doi.org/10.1098/rspb.2016.2335

Brown, J. H. (1984). On the Relationship between Abundance and Distribution of Species. The American Naturalist, 124(2), 255-279. https://doi.org/10.1086/284267 
Burns, P., Clark, M., Salas, L., Hancock, S., Leland, D., Jantz, P., Dubayah, R., \& Goetz, S. J. (2020). Incorporating canopy structure from simulated GEDI lidar into bird species distribution models. Environmental Research Letters, 15(9), 095002. https://doi.org/10.1088/1748-9326/ab80ee

Busby, J. R. (1991). BIOCLIM - A bioclimate analysis and prediction system. In C. R. Margules \& M. P.

Capurucho, J. M. G., Ashley, M. V., Tsuru, B. R., Cooper, J. C., \& Bates, J. M. (2020). Dispersal ability correlates with range size in Amazonian habitat-restricted birds. Proceedings of the Royal Society B: Biological Sciences, 287(1939), 20201450. https://doi.org/10.1098/rspb.2020.1450

Caruso, C. M., Martin, R. A., Sletvold, N., Morrissey, M. B., Wade, M. J., Augustine, K. E., Carlson, S.

Caughley, G. (1994). Directions in conservation biology. Journal of Animal Ecology, 63(2), 215-244. https://doi.org/10.2307/5542

Ceballos, G., Ehrlich, P. R., Barnosky, A. D., García, A., Pringle, R. M., \& Palmer, T. M. (2015). Accelerated modern human-induced species losses: Entering the sixth mass extinction. Science Advances, 1(5), e1400253. https://doi.org/10.1126/sciadv.1400253

Chakraborty, A., Gelfand, A. E., Wilson, A. M., Latimer, A. M., \& John A. Silander, J. (2010). Modeling large scale species abundance with latent spatial processes. The Annals of Applied Statistics, 4(3), 1403-1429. https://doi.org/10.1214/10-AOAS335

Claramunt, S., Derryberry, E. P., Remsen, J. V., \& Brumfield, R. T. (2012). High dispersal ability inhibits speciation in a continental radiation of passerine birds. Proceedings of the Royal Society B:

Biological Sciences, 279(1733), 1567-1574. https://doi.org/10.1098/rspb.2011.1922 
815 Colwell, R. K., Brehm, G., Cardelús, C. L., Gilman, A. C., \& Longino, J. T. (2008). Global warming, elevational range shifts, and lowland biotic attrition in the wet tropics. Science, 322(5899), 258261. https://doi.org/10.1126/science. 1162547

Corre, M. L., Dussault, C., \& Côté, S. D. (2020). Where to spend the winter? The role of intraspecific

Cowles, R. B., \& Bogert, C. M. (1944). A preliminary study of the thermal requirements of desert reptiles. Bulletin of the American Museum of Natural History, 83(5), 261-296.

Dalgarno, S., Mersey, J. E., Gedalof, Z., \& Lemon, M. (2017). Species-environment associations and predicted distribution of Black Oystercatcher breeding pairs in Haida Gwaii, British Columbia, Canada. Avian Conservation and Ecology, 12(2), art9. https://doi.org/10.5751/ACE-01094-

Dallas, T. A., Santini, L., Decker, R., \& Hastings, A. (2020). Weighing the Evidence for the AbundantCenter Hypothesis. Biodiversity Informatics, 15(3), 81-91. https://doi.org/10.17161/bi.v15i3.11989

Danner, R. M., \& Greenberg, R. (2015). A critical season approach to Allen's rule: Bill size declines with winter temperature in a cold temperate environment. Journal of Biogeography, 42(1), 114-120.

Deutsch, C. A., Tewksbury, J. J., Huey, R. B., Sheldon, K. S., Ghalambor, C. K., Haak, D. C., \& Martin, P. R. (2008). Impacts of climate warming on terrestrial ectotherms across latitude. Proceedings of the National Academy of Sciences, 105(18), 6668-6672. the Boreal Owl and Northern Saw-whet Owl in the boreal region of Alberta, Canada. Avian Conservation and Ecology, 14(2), art14. https://doi.org/10.5751/ACE-01445-140214 
Dormann, C. F., Purschke, O., Márquez, J. R. G., Lautenbach, S., \& Schröder, B. (2008). Components of Uncertainty in Species Distribution Analysis: A Case Study of the Great Grey Shrike. Ecology, 89(12), 3371-3386. https://doi.org/10.1890/07-1772.1

Drew, A., \& Collazo, J. (2014). Bayesian networks as a framework to step-down and support Strategic Habitat Conservation of data-poor species: A case study with King Rail (Rallus elegans) in Eastern North Carolina and Southeastern Virginia. US Fish and Wildlife Service. https://doi.org/10.13140/2.1.4430.5920

Ducatez, S., Sol, D., Sayol, F., \& Lefebvre, L. (2020). Behavioural plasticity is associated with reduced

Dunn, P. O., \& Møller, A. P. (2019). Effects of climate change on birds. Oxford University Press.

Dvorský, M., Macek, M., Kopecký, M., Wild, J., \& Doležal, J. (2017). Niche asymmetry of vascular plants increases with elevation. Journal of Biogeography, 44(6), 1418-1425. https://doi.org/10.1111/jbi.13001

Early, R., \& Sax, D. F. (2014). Climatic niche shifts between species' native and naturalized ranges raise concern for ecological forecasts during invasions and climate change. Global Ecology and Biogeography, 23(12), 1356-1365. https://doi.org/10.1111/geb.12208

Elith, J. (2017). Predicting Distributions of Invasive Species. In Invasive Species: Risk Assessment and Management (pp. 93-129). Cambridge University Press.

Elith, J., H. Graham, C., P. Anderson, R., Dudík, M., Ferrier, S., Guisan, A., J. Hijmans, R., Huettmann, F., R. Leathwick, J., Lehmann, A., Li, J., G. Lohmann, L., A. Loiselle, B., Manion, G., Moritz, C., Nakamura, M., Nakazawa, Y., McC. M. Overton, J., Townsend Peterson, A., ... E. Zimmermann, N. (2006). Novel methods improve prediction of species' distributions from occurrence data. Ecography, 29(2), 129-151. https://doi.org/10.1111/j.2006.0906-7590.04596.x 
863

Elith, J., \& Leathwick, J. (2007). Predicting species distributions from museum and herbarium records using multiresponse models fitted with multivariate adaptive regression splines. Diversity and Distributions, 13(3), 265-275. https://doi.org/10.1111/j.1472-4642.2007.00340.x

Elith, J., Leathwick, J. R., \& Hastie, T. (2008). A working guide to boosted regression trees. Journal of Animal Ecology, 77(4), 802-813. https://doi.org/10.1111/j.1365-2656.2008.01390.x

Elsen, P. R., Tingley, M. W., Kalyanaraman, R., Ramesh, K., \& Wilcove, D. S. (2017). The role of competition, ecotones, and temperature in the elevational distribution of Himalayan birds. Ecology, 98(2), 337-348. https://doi.org/10.1002/ecy.1669

Elton, C. (1927). Animal ecology. Sidgwick \& Jackson.

Faaborg, J., Holmes, R. T., Anders, A. D., Bildstein, K. L., Dugger, K. M., Gauthreaux, S. A., Heglund, P., Hobson, K. A., Jahn, A. E., Johnson, D. H., Latta, S. C., Levey, D. J., Marra, P. P., Merkord, C. L., Nol, E., Rothstein, S. I., Sherry, T. W., Sillett, T. S., Thompson, F. R., \& Warnock, N. (2010). Recent advances in understanding migration systems of New World land birds. Ecological Monographs, 80(1), 3-48. https://doi.org/10.1890/09-0395.1

Feeley, K. J., Rehm, E. M., \& Machovina, B. (2012). perspective: The responses of tropical forest species to global climate change: acclimate, adapt, migrate, or go extinct? Frontiers of Biogeography, 4(2). https://doi.org/10.21425/F5FBG12621

Fick, S. E., \& Hijmans, R. J. (2017). WorldClim 2: New 1-km spatial resolution climate surfaces for global land areas. International Journal of Climatology, 37(12), 4302-4315. https://doi.org/10.1002/joc.5086

Freeman, B. G., Freeman, A. M. C., \& Hochachka, W. M. (2016). Asymmetric interspecific aggression in New Guinean songbirds that replace one another along an elevational gradient. Ibis, 158(4), 726737. https://doi.org/10.1111/ibi.12384

Freeman, B. G., \& Mason, N. A. (2015). The geographic distribution of a tropical montane bird is limited by a tree: Acorn Woodpeckers (Melanerpes formicivorus) and Colombian oaks (Quercus 
humboldtii) in the Northern Andes. PLOS ONE, 10(6), e0128675. https://doi.org/10.1371/journal.pone.0128675

Freeman, B. G., Scholer, M. N., Ruiz-Gutierrez, V., \& Fitzpatrick, J. W. (2018). Climate change causes upslope shifts and mountaintop extirpations in a tropical bird community. Proceedings of the

Freeman, B. G., Tobias, J. A., \& Schluter, D. (2019). Behavior influences range limits and patterns of coexistence across an elevational gradient in tropical birds. Ecography, 42(11), 1832-1840.

Gallagher, R. V., Falster, D. S., Maitner, B. S., Salguero-Gómez, R., Vandvik, V., Pearse, W. D., Schneider, F. D., Kattge, J., Poelen, J. H., Madin, J. S., Ankenbrand, M. J., Penone, C., Feng, X.,

Garcia-R, J. C., \& Matzke, N. J. (2021). Trait-dependent dispersal in rails (Aves: Rallidae): Historical biogeography of a cosmopolitan bird clade. Molecular Phylogenetics and Evolution, 159, 107106. https://doi.org/10.1016/j.ympev.2021.107106

Gardner, J. L., Peters, A., Kearney, M. R., Joseph, L., \& Heinsohn, R. (2011). Declining body size: A third universal response to warming? Trends in Ecology \& Evolution, 26(6), 285-291. https://doi.org/10.1016/j.tree.2011.03.005

Goetz, S. J., Steinberg, D., Betts, M. G., Holmes, R. T., Doran, P. J., Dubayah, R., \& Hofton, M. (2010).

910 Grady, J. M., Maitner, B. S., Winter, A. S., Kaschner, K., Tittensor, D. P., Record, S., Smith, F. A., Metabolic asymmetry and the global diversity of marine predators. Science, 363(6425). https://doi.org/10.1126/science.aat4220 
914 Graham, C. H., Elith, J., Hijmans, R. J., Guisan, A., Peterson, A. T., \& Loiselle, B. A. (2008). The influence of spatial errors in species occurrence data used in distribution models. Journal of

917 Graham, R. W., Lundelius, E. L., Graham, M. A., Schroeder, E. K., Toomey, R. S., Anderson, E.,

918 Barnosky, A. D., Burns, J. A., Churcher, C. S., Grayson, D. K., Guthrie, R. D., Harington, C. R.,

919 Jefferson, G. T., Martin, L. D., McDonald, H. G., Morlan, R. E., Semken, H. A., Webb, S. D.,

920 Werdelin, L., \& Wilson, M. C. (1996). Spatial Response of Mammals to Late Quaternary

$921 \quad$ Environmental Fluctuations. Science, 272(5268), 1601-1606.

922 https://doi.org/10.1126/science.272.5268.1601

923 Grant, P. R., \& Grant, B. R. (2020). How and Why Species Multiply. In How and Why Species Multiply.

924 Princeton University Press.

925 https://www.degruyter.com/document/doi/10.1515/9781400837946/html

926 Grant, P. R., \& Weiner, J. (2017). Ecology and Evolution of Darwin's Finches (Princeton Science Library Edition): Princeton Science Library Edition.

928 Guisan, A., \& Zimmermann, N. E. (2000). Predictive habitat distribution models in ecology. Ecological Modelling, 135(2), 147-186. https://doi.org/10.1016/S0304-3800(00)00354-9

930 Haldane, J. B. S. (1956). The relation between density regulation and natural selection. Proceedings of the Royal Society of London. Series B - Biological Sciences, 145(920), 306-308.

933 Hallman, T. A., \& Robinson, W. D. (2020). Comparing multi- and single-scale species distribution and 934 abundance models built with the boosted regression tree algorithm. Landscape Ecology, 35(5), 935 1161-1174. https://doi.org/10.1007/s10980-020-01007-7

936 Hamilton, S. H., Pollino, C. A., \& Jakeman, A. J. (2015). Habitat suitability modelling of rare species 937 using Bayesian networks: Model evaluation under limited data. Ecological Modelling, 299, 64938 78. https://doi.org/10.1016/j.ecolmodel.2014.12.004 
Harris, I., Jones, P. D., Osborn, T. J., \& Lister, D. H. (2014). Updated high-resolution grids of monthly climatic observations - the CRU TS3.10 Dataset. International Journal of Climatology, 34(3), 623-642. https://doi.org/10.1002/joc.3711

He, K. S., Bradley, B. A., Cord, A. F., Rocchini, D., Tuanmu, M.-N., Schmidtlein, S., Turner, W., Wegmann, M., \& Pettorelli, N. (2015). Will remote sensing shape the next generation of species

Heim, W., Heim, R. J., Beermann, I., Burkovskiy, O. A., Gerasimov, Y., Ktitorov, P., Ozaki, K., Panov, I., Sander, M. M., Sjöberg, S., Smirenski, S. M., Thomas, A., Tøttrup, A. P., Tiunov, I. M., distribution models? Remote Sensing in Ecology and Conservation, 1(1), 4-18.

Hefley, T. J., \& Hooten, M. B. (2015). On the existence of maximum likelihood estimates for presencehttps://doi.org/10.1002/rse2.7

Helm, B., Van Doren, B. M., Hoffmann, D., \& Hoffmann, U. (2019). Evolutionary response to climate change in migratory Pied Flycatchers. Current Biology, 29(21), 3714-3719.e4. https://doi.org/10.1016/j.cub.2019.08.072 Willemoes, M., Hölzel, N., Thorup, K., \& Kamp, J. (2020). Using geolocator tracking data and

Herbert, J. A., Chakraborty, A., Naylor, L. W., Beatty, W. S., \& Krementz, D. G. (2018). Effects of wintering dabbling ducks in the Arkansas Mississippi Alluvial Valley: Implications for waterfowl management beyond the mallard. Wildlife Biology, 2021(1). https://doi.org/10.2981/wlb.00792 
964

965

966

967

968

969

970

971

972

973

974

975

976

977

978

979

980

981

982

983

984

985

986

987

988

Holland, R. A., Wikelski, M., Kümmeth, F., \& Bosque, C. (2009). The secret life of oilbirds: New insights into the movement ecology of a unique avian frugivore. PLOS ONE, 4(12), e8264. https://doi.org/10.1371/journal.pone.0008264

Holt, R. D., Keitt, T. H., Lewis, M. A., Maurer, B. A., \& Taper, M. L. (2005). Theoretical models of species' borders: Single species approaches. Oikos, 108(1), 18-27. https://doi.org/10.1111/j.00301299.2005.13147.x

Hsiung, A. C., Boyle, W. A., Cooper, R. J., \& Chandler, R. B. (2018). Altitudinal migration: Ecological drivers, knowledge gaps, and conservation implications. Biological Reviews, 93(4), 2049-2070. https://doi.org/10.1111/brv.12435

Huey, R. B., Hertz, P. E., \& Sinervo, B. (2003). Behavioral drive versus behavioral inertia in evolution: A null model approach. The American Naturalist, 161(3), 357-366. https://doi.org/10.1086/346135

Huey, R. B., Kearney, M. R., Krockenberger, A., Holtum, J. A. M., Jess, M., \& Williams, S. E. (2012). Predicting organismal vulnerability to climate warming: Roles of behaviour, physiology and adaptation. Philosophical Transactions of the Royal Society B: Biological Sciences, 367(1596), 1665-1679. https://doi.org/10.1098/rstb.2012.0005

Jaeger, R. G. (1970). Potential Extinction Through Competition Between Two Species of Terrestrial Salamanders. Evolution, 24(3), 632-642. https://doi.org/10.2307/2406842

Jahn, A. E., Buechley, E., Bugoni, L., Cereghetti, J., Repenning, M., Marra, P. P., \& Ryder, T. B. (2021). Variable Seasonal Movement Dynamics Among Individual Snail Kites (Rostrhamus sociabilis) In South America. Journal of Raptor Research. https://doi.org/10.3356/JRR-20-77

Jahn, A. E., Cueto, V. R., Fontana, C. S., Guaraldo, A. C., Levey, D. J., Marra, P. P., \& Ryder, T. B. (2020). Bird migration within the Neotropics. The Auk, 137(ukaa033). https://doi.org/10.1093/auk/ukaa033

Jahn, A. E., Cueto, V. R., Fox, J. W., Husak, M. S., Kim, D. H., Landoll, D. V., Ledezma, J. P., Lepage, H. K., Levey, D. J., Murphy, M. T., \& Renfrew, R. B. (2013). Migration timing and wintering 
areas of three species of flycatchers (Tyrannus) breeding in the Great Plains of North America. The Auk, 130(2), 247-257. https://doi.org/10.1525/auk.2013.13010

991 Jahn, A. E., Levey, D. J., \& Smith, K. G. (2004). Reflections across hemispheres: A system-wide approach to New World bird migration. The Auk, 121(4), 1005-1013.

Jahn, A. E., Seavy, N., Bejarano, V., Guzmán, M. B., Provinciato, I. C. C., Pizo, M., \& MacPherson, M. (2016). Intra-tropical migration and wintering areas of Fork-tailed Flycatchers (Tyrannus

Jankowski, J. E., Londoño, G. A., Robinson, S. K., \& Chappell, M. A. (2013). Exploring the role of physiology and biotic interactions in determining elevational ranges of tropical animals. Ecography, 36, 001-012.

1001

Jankowski, J. E., Robinson, S. K., \& Levey, D. J. (2010). Squeezed at the top: Interspecific aggression may constrain elevational ranges in tropical birds. Ecology, 91(7), 1877-1884.

Jansen, F., \& Oksanen, J. (2013). How to model species responses along ecological gradients - HuismanOlff-Fresco models revisited. Journal of Vegetation Science, 24(6), 1108-1117. https://doi.org/10.1111/jvs. 12050

Janzen, D. H. (1967). Why mountain passes are higher in the tropics. The American Naturalist, 101(919), 233-249.

1008 Jarnevich, C. S., Talbert, M., Morisette, J., Aldridge, C., Brown, C. S., Kumar, S., Manier, D., Talbert, C., 1009 \& Holcombe, T. (2017). Minimizing effects of methodological decisions on interpretation and 1010 prediction in species distribution studies: An example with background selection. Ecological 1011 Modelling, 363, 48-56. https://doi.org/10.1016/j.ecolmodel.2017.08.017

1012 Jiguet, F., Gadot, A.-S., Julliard, R., Newson, S. E., \& Couvet, D. (2007). Climate envelope, life history 1013 traits and the resilience of birds facing global change. Global Change Biology, 13(8), 1672-1684. 1014 https://doi.org/10.1111/j.1365-2486.2007.01386.x 
1015 Jirinec, V., Isdell, R. E., \& Leu, M. (2016). Prey availability and habitat structure explain breeding space

1016

1017

1018

1019

1020

1021

1022

1023

1024

1025

1026

1027

1028

1029

1030

1031

1032

1033

1034

1035

1036

1037

1038 use of a migratory songbird. The Condor, 118(2), 309-328. https://doi.org/10.1650/CONDOR$15-140.1$

Jones, J. (2001). Habitat selection studies in avian ecology: A critical review. The Auk, 118(2), 557-562. https://doi.org/10.1093/auk/118.2.557

Jones, M. C., \& Cheung, W. W. L. (2015). Multi-model ensemble projections of climate change effects on global marine biodiversity. ICES Journal of Marine Science, 72(3), 741-752. https://doi.org/10.1093/icesjms/fsu172

Kapos, V. (1989). Effects of isolation on the water status of forest patches in the Brazilian Amazon. Journal of Tropical Ecology, 5(2), 173-185. https://doi.org/10.1017/S0266467400003448

Kearney, M. (2006). Habitat, environment and niche: What are we modelling? Oikos, 115(1), 186-191. https://doi.org/10.1111/j.2006.0030-1299.14908.x

Kearney, M., \& Porter, W. (2009). Mechanistic niche modelling: Combining physiological and spatial data to predict species' ranges. Ecology Letters, 12(4), 334-350. https://doi.org/10.1111/j.14610248.2008.01277.x

Kearney, M. R., Porter, W. P., \& Murphy, S. A. (2016). An estimate of the water budget for the endangered night parrot of Australia under recent and future climates. Climate Change Responses, 3(1), 14. https://doi.org/10.1186/s40665-016-0027-y

Kitzes, J., \& Schricker, L. (2019). The necessity, promise and challenge of automated biodiversity surveys. Environmental Conservation, 46(4), 247-250. https://doi.org/10.1017/S0376892919000146

Kokko, H., Gunnarsson, T. G., Morrell, L. J., \& Gill, J. A. (2006). Why do female migratory birds arrive later than males? Journal of Animal Ecology, 75(6), 1293-1303. https://doi.org/10.1111/j.13652656.2006.01151.x 
1039

1040

1041

1042

1043

1044

1045

1046

1047

1048

1049

1050

1051

1052

1053

1054

1055

1056

1057

1058

1059

1060

1061

1062

1063

König, C., Wüest, R. O., Graham, C. H., Karger, D. N., Sattler, T., Zimmermann, N. E., \& Zurell, D. (2021). Scale dependency of joint species distribution models challenges interpretation of biotic interactions. Journal of Biogeography, 0, 1-11. https://doi.org/10.1111/jbi.14106

Kottler, E. J., Dickman, E. E., Sexton, J. P., Emery, N. C., \& Franks, S. J. (2021). Draining the Swamping Hypothesis: Little Evidence that Gene Flow Reduces Fitness at Range Edges. Trends in Ecology \& Evolution, 36(6), 533-544. https://doi.org/10.1016/j.tree.2021.02.004

La Sorte, F. A., Lepczyk, C. A., Burnett, J. L., Hurlbert, A. H., Tingley, M. W., \& Zuckerberg, B. (2018). Opportunities and challenges for big data ornithology. The Condor, 120(2), 414-426. https://doi.org/10.1650/CONDOR-17-206.1

Latimer, C. E., \& Zuckerberg, B. (2021). Habitat loss and thermal tolerances influence the sensitivity of resident bird populations to winter weather at regional scales. Journal of Animal Ecology, 90(2), 317-329. https://doi.org/10.1111/1365-2656.13332

Lavretsky, P., McInerney, N. R., Mohl, J. E., Brown, J. I., James, H. F., McCracken, K. G., \& Fleischer, R. C. (2020). Assessing changes in genomic divergence following a century of human-mediated secondary contact among wild and captive-bred ducks. Molecular Ecology, 29(3), 578-595. https://doi.org/10.1111/mec. 15343

Léandri-Breton, D.-J., \& Bêty, J. (2020). Vulnerability to predation may affect species distribution: Plovers with broader arctic breeding range nest in safer habitat. Scientific Reports, 10(1), 5032. https://doi.org/10.1038/s41598-020-61956-6

Leclerc, C., Villéger, S., Marino, C., \& Bellard, C. (2020). Global changes threaten functional and taxonomic diversity of insular species worldwide. Diversity and Distributions, 26(4), 402-414. https://doi.org/10.1111/ddi.13024

Lees, A. C., Rosenberg, K. V., Ruiz-Gutierrez, V., Marsden, S., Schulenberg, T. S., \& Rodewald, A. D. (2020). A roadmap to identifying and filling shortfalls in Neotropical ornithology. The Auk, 137(4), NA. https://doi.org/10.1093/auk/ukaa048 
Lei, Y., \& Liu, Q. (2021). Tolerance niche expansion and potential distribution prediction during Asian openbill bird range expansion. Ecology and Evolution, 00, 1-13. https://doi.org/10.1002/ece3.7456

1067 Londoño, G. A., Chappell, M. A., Castañeda, M. del R., Jankowski, J. E., \& Robinson, S. K. (2015). Basal metabolism in tropical birds: Latitude, altitude, and the 'pace of life.' Functional Ecology,

1070 Londoño, G. A., Chappell, M. A., Jankowski, J. E., \& Robinson, S. K. (2017). Do thermoregulatory costs limit altitude distributions of Andean forest birds? Functional Ecology, 31(1), 204-215.

Louthan, A. M., Doak, D. F., \& Angert, A. L. (2015). Where and when do species interactions set range limits? Trends in Ecology \& Evolution, 30(12), 780-792. https://doi.org/10.1016/j.tree.2015.09.011 Filho, J. A. F. (2013). A straightforward conceptual approach for evaluating spatial conservation priorities under climate change. Biodiversity and Conservation, 22(2), 483-495. https://doi.org/10.1007/s10531-012-0424-x

Lukas, J., Auer, F., Goldhammer, T., Krause, J., Romanczuk, P., Klamser, P., Arias-Rodriguez, L., \& Bierbach, D. (2021). Diurnal Changes in Hypoxia Shape Predator-Prey Interaction in a Birdin population studies of rare species that are detected imperfectly. Ecology, 86(5), 1101-1113. https://doi.org/10.1890/04-1060 predicting avian responses to climate change. 
MacPherson, M. P., Jahn, A. E., \& Mason, N. A. (2021). Morphology of migration: Associations between wing shape, bill morphology, and migration in kingbirds (Tyrannus). BioRxiv, 2021.04.06.438708. https://doi.org/10.1101/2021.04.06.438708

MacPherson, M. P., Jahn, A. E., Murphy, M. T., Kim, D. H., Cueto, V. R., Tuero, D. T., \& Hill, E. D. (2018). Follow the rain? Environmental drivers of Tyrannus migration across the New World. The Auk, 135(4), 881-894. https://doi.org/10.1642/AUK-17-209.1

MacPherson, M. P., Webb, E. B., Raedeke, A., Mengel, D., \& Nelson, F. (2018). A review of Bayesian belief network models as decision-support tools for wetland conservation: Are water birds potential umbrella taxa? Biological Conservation, 226, 215-223. https://doi.org/10.1016/j.biocon.2018.08.001

Maggini, R., Lehmann, A., Kéry, M., Schmid, H., Beniston, M., Jenni, L., \& Zbinden, N. (2011). Are Swiss birds tracking climate change?: Detecting elevational shifts using response curve shapes.

1102 Manel, S., Dias, J. M., Buckton, S. T., \& Ormerod, S. J. (1999). Alternative methods for predicting species distribution: An illustration with Himalayan river birds. Journal of Applied Ecology,

1105 Marini, M. Â., Barbet-Massin, M., Lopes, L. E., \& Jiguet, F. (2009). Predicted climate-driven bird distribution changes and forecasted conservation conflicts in a Neotropical savanna. Conservation

1108 Matuoka, M. A., Benchimol, M., Almeida-Rocha, J. M. de, \& Morante-Filho, J. C. (2020). Effects of anthropogenic disturbances on bird functional diversity: A global meta-analysis. Ecological Indicators, 116, 106471. https://doi.org/10.1016/j.ecolind.2020.106471

1112 learned in the golden age of bio-logging. The Auk, 135(4), 834-856.

1113 https://doi.org/10.1642/AUK-17-202.1 
1114 Merow, C., Smith, M. J., \& Silander, J. A., Jr. (2013). A practical guide to MaxEnt for modeling species’ distributions: What it does, and why inputs and settings matter. Ecography, 36(10), 1058-1069.

1117 Mi, C., Huettmann, F., Guo, Y., Han, X., \& Wen, L. (2017). Why choose Random Forest to predict rare https://doi.org/10.1111/j.1600-0587.2013.07872.x

1123 Moore, R. P., Robinson, W. D., Lovette, I. J., \& Robinson, T. R. (2008). Experimental evidence for extreme dispersal limitation in tropical forest birds. Ecology Letters, 11(9), 960-968.

Mora, C., Frazier, A. G., Longman, R. J., Dacks, R. S., Walton, M. M., Tong, E. J., Sanchez, J. J., Kaiser, Koop, D., Swanson, A., \& Young, N. E. (2013). VisTrails SAHM: Visualization and workflow management for species habitat modeling. Ecography, 36(2), 129-135.

1134 Moritz, C., \& Agudo, R. (2013). The future of species under climate change: Resilience or decline? Science, 341(6145), 504-508. https://doi.org/10.1126/science.1237190

1136 Morris, W. F., \& Doak, D. F. (2002). Quantitative conservation biology: Theory and practice of 1137 population viability analysis. Sinauer Associates. 
1138 Morrison, M. L. (1986). Bird populations as indicators of environmental change. In R. F. Johnston (Ed.), Current Ornithology: Volume 3 (pp. 429-451). Springer US. https://doi.org/10.1007/978-1-46156784-4_10

Nakao, K., Higa, M., Tsuyama, I., Matsui, T., Horikawa, M., \& Tanaka, N. (2013). Spatial conservation effects of mosaic structure on alpha and beta diversity of bird assemblages in a human-modified

1148 Nilsson, C., Klaassen, R. H. G., \& Alerstam, T. (2013). Differences in speed and duration of bird migration between spring and autumn. The American Naturalist, 181(6), 837-845.

Oksanen, J., \& Minchin, P. R. (2002). Continuum theory revisited: What shape are species responses along ecological gradients? Ecological Modelling, 157(2), 119-129.

1154 Oppel, S., Meirinho, A., Ramírez, I., Gardner, B., O’Connell, A. F., Miller, P. I., \& Louzao, M. (2012). https://doi.org/10.1016/S0304-3800(02)00190-4 Comparison of five modelling techniques to predict the spatial distribution and abundance of seabirds. Biological Conservation, 156, 94-104. https://doi.org/10.1016/j.biocon.2011.11.013

Palacio, F. X., \& Girini, J. M. (2018). Biotic interactions in species distribution models enhance model performance and shed light on natural history of rare birds: A case study using the straight-billed reedhaunter Limnoctites rectirostris. Journal of Avian Biology, 49(11), e01743. https://doi.org/10.1111/jav.01743

Palma, A. C., Goosem, M., Fensham, R. J., Goosem, S., Preece, N. D., Stevenson, P. R., \& Laurance, S. G. W. (2020). Dispersal and recruitment limitations in secondary forests. Journal of Vegetation Science, 32, e12975. https://doi.org/10.1111/jvs.12975 
1164 Papeş, M., Peterson, A. T., \& Powell, G. V. N. (2012). Vegetation dynamics and avian seasonal migration: Clues from remotely sensed vegetation indices and ecological niche modelling.

1167 Parmesan, C., \& Matthews, J. (2005). Biological Impacts of Climate Change. https://doi.org/10.17226/12491

1169 Parmesan, C., \& Yohe, G. (2003). A globally coherent fingerprint of climate change impacts across natural systems. Nature, 421(6918), 37-42. https://doi.org/10.1038/nature01286

1171 Pearl, J. (1985). Bayesian networks: A model of self-activated memory for evidential reasoning. Proceedings of the 7th Conference of the Cognitive Science Society.

1173 Pearson, R. G., \& Dawson, T. P. (2003). Predicting the impacts of climate change on the distribution of species: Are bioclimate envelope models useful? Global Ecology and Biogeography, 12(5), 361371. https://doi.org/10.1046/j.1466-822X.2003.00042.x Madagascar. Journal of Biogeography, 34(1), 102-117. https://doi.org/10.1111/j.13652699.2006.01594.x

Pecl, G. T., Araújo, M. B., Bell, J. D., Blanchard, J., Bonebrake, T. C., Chen, I.-C., Clark, T. D., Colwell, B., Hobday, A. J., Janion-Scheepers, C., Jarzyna, M. A., Jennings, S., ... Williams, S. E. (2017). Biodiversity redistribution under climate change: Impacts on ecosystems and human well-being. Science, 355(6332). https://doi.org/10.1126/science.aai9214

Pérez-Granados, C., Bota, G., Giralt, D., Barrero, A., Gómez-Catasús, J., Rosa, D. B.-D. L., \& Traba, J. (2019). Vocal activity rate index: A useful method to infer terrestrial bird abundance with acoustic monitoring. Ibis, 161(4), 901-907. https://doi.org/10.1111/ibi.12728

Pérez-Granados, C., \& Schuchmann, K.-L. (2020). Monitoring the annual vocal activity of two enigmatic nocturnal Neotropical birds: The Common Potoo (Nyctibius griseus) and the Great Potoo 
(Nyctibius grandis). Journal of Ornithology, 161(4), 1129-1141. https://doi.org/10.1007/s10336020-01795-4

1192 Phillips, S. J., Anderson, R. P., \& Schapire, R. E. (2006). Maximum entropy modeling of species geographic distributions. Ecological Modelling, 190(3), 231-259.

1195 Pierson, J. C., Beissinger, S. R., Bragg, J. G., Coates, D. J., Oostermeijer, J. G. B., Sunnucks, P., Schumaker, N. H., Trotter, M. V., \& Young, A. G. (2015). Incorporating evolutionary processes

Pollock, H. S., Brawn, J. D., \& Cheviron, Z. A. (2021). Heat tolerances of temperate and tropical birds and their implications for susceptibility to climate warming. Functional Ecology, 35(1), 93-104. https://doi.org/10.1111/1365-2435.13693

Poloczanska, E. S., Brown, C. J., Sydeman, W. J., Kiessling, W., Schoeman, D. S., Moore, P. J., Brander, K., Bruno, J. F., Buckley, L. B., Burrows, M. T., Duarte, C. M., Halpern, B. S., Holding, J., Kappel, C. V., O’Connor, M. I., Pandolfi, J. M., Parmesan, C., Schwing, F., Thompson, S. A., \&

Porter, W. P., Mitchell, J. W., Beckman, W. A., \& DeWitt, C. B. (1973). Behavioral implications of Richardson, A. J. (2013). Global imprint of climate change on marine life. Nature Climate mechanistic ecology. Oecologia, 13(1), 1-54. https://doi.org/10.1007/BF00379617 Change, 3(10), 919-925. https://doi.org/10.1038/nclimate1958

1212 Radchuk, V., Reed, T., Teplitsky, C., van de Pol, M., Charmantier, A., Hassall, C., Adamík, P., 1213 Adriaensen, F., Ahola, M. P., Arcese, P., Miguel Avilés, J., Balbontin, J., Berg, K. S., Borras, A., 1214 Burthe, S., Clobert, J., Dehnhard, N., de Lope, F., Dhondt, A. A., ... Kramer-Schadt, S. (2019). 
Adaptive responses of animals to climate change are most likely insufficient. Nature Communications, 10(1), 3109. https://doi.org/10.1038/s41467-019-10924-4

Radosavljevic, A., \& Anderson, R. P. (2014). Making better Maxent models of species distributions: Complexity, overfitting and evaluation. Journal of Biogeography, 41(4), 629-643. https://doi.org/10.1111/jbi.12227

Randin, C. F., Ashcroft, M. B., Bolliger, J., Cavender-Bares, J., Coops, N. C., Dullinger, S., Dirnböck, T., Eckert, S., Ellis, E., Fernández, N., Giuliani, G., Guisan, A., Jetz, W., Joost, S., Karger, D., Lembrechts, J., Lenoir, J., Luoto, M., Morin, X., ... Payne, D. (2020). Monitoring biodiversity in the Anthropocene using remote sensing in species distribution models. Remote Sensing of Environment, 239, 111626. https://doi.org/10.1016/j.rse.2019.111626

Rappole, J. H. (1995). The ecology of migrant birds: A neotropical perspective. Smithsonian institution Press.

Reed, J. M., Boulinier, T., Danchin, E., \& Oring, L. W. (1999). Informed Dispersal. In V. Nolan, E. D. Ketterson, \& C. F. Thompson (Eds.), Current Ornithology (pp. 189-259). Springer US. https://doi.org/10.1007/978-1-4757-4901-4_5

Rehm, E., \& Feeley, K. J. (2016). Many species risk mountain top extinction long before they reach the top. Frontiers of Biogeography, 8(1). https://doi.org/10.21425/F5FBG27788

Renfrew, R. B., Kim, D., Perlut, N., Smith, J., Fox, J., \& Marra, P. P. (2013). Phenological matching across hemispheres in a long-distance migratory bird. Diversity and Distributions, 19(8), 10081019. https://doi.org/10.1111/ddi.12080

Reznick, D., Baxter, R. J., \& Endler, J. (1994). Long-term studies of tropical stream fish communities: The use of field notes and museum collections to reconstruct communities of the past. Integrative and Comparative Biology, 34(3), 452-462. https://doi.org/10.1093/icb/34.3.452

Ribas, C. C., Aleixo, A., Gubili, C., d'Horta, F. M., Brumfield, R. T., \& Cracraft, J. (2018). Biogeography and diversification of Rhegmatorhina (Aves: Thamnophilidae): Implications for the evolution of 
Amazonian landscapes during the Quaternary. Journal of Biogeography, 45(4), 917-928. https://doi.org/10.1111/jbi.13169

1242 Ribas, C. C., Aleixo, A., Nogueira, A. C. R., Miyaki, C. Y., \& Cracraft, J. (2012). A palaeobiogeographic

Riddell, E. A., Iknayan, K. J., Hargrove, L., Tremor, S., Patton, J. L., Ramirez, R., Wolf, B. O., \& Beissinger, S. R. (2021). Exposure to climate change drives stability or collapse of desert mammal and bird communities. Science, 371(6529), 633-636. https://doi.org/10.1126/science.abd4605

Riotte-Lambert, L., \& Matthiopoulos, J. (2020). Environmental Predictability as a Cause and Consequence of Animal Movement. Trends in Ecology and Evolution, 35(2), 163-174. https://doi.org/10.1016/j.tree.2019.09.009 species, different histories: Comparative phylogeography of two bird species associated with Amazonian open vegetation. Biological Journal of the Linnean Society, 132(1), 161-173. https://doi.org/10.1093/biolinnean/blaa167

1257 Rosado, B. H. P., Figueiredo, M. S. L., Mattos, E. A. de, \& Grelle, C. E. V. (2016). Eltonian shortfall due to the Grinnellian view: Functional ecology between the mismatch of niche concepts. Ecography,

1260 Roslin, T., Antão, L., Hällfors, M., Meyke, E., Lo, C., Tikhonov, G., Delgado, M. del M., Gurarie, E., 
1265 Sander, M., Chamberlain, D., Mermillon, C., Alba, R., Jähnig, S., Rosselli, D., \& Lisovski, S. (2020). Reduced breeding success suggests trophic mismatch despite timely arrival in an alpine songbird [Preprint]. https://assets.researchsquare.com/files/rs-137126/v1/650443e6-45ba-470a-814c47dde4d049d7.pdf

Saupe, E. E., Barve, V., Myers, C. E., Soberón, J., Barve, N., Hensz, C. M., Peterson, A. T., Owens, H. L., \& Lira-Noriega, A. (2012). Variation in niche and distribution model performance: The need

Sax, D. F., Early, R., \& Bellemare, J. (2013). Niche syndromes, species extinction risks, and management under climate change. Trends in Ecology \& Evolution, 28(9), 517-523. https://doi.org/10.1016/j.tree.2013.05.010 reduce animal's exposure to climate extremes. Global Change Biology, 20(2), 495-503. https://doi.org/10.1111/gcb.12439 heterogeneity in structurally complex tropical rain forests. Biotropica, 49(1), 35-44.

1283 Sekercioglu, C. H. (2010). Partial migration in tropical birds: The frontier of movement ecology. Journal of Animal Ecology, 79(5), 933-936. https://doi.org/10.1111/j.1365-2656.2010.01739.x

1285 Şekercioğlu, C., Wenny, D. G., \& Whelan, C. J. (2019). Why birds matter: Avian ecological function and 1286 ecosystem services.

1287 http://chicago.universitypressscholarship.com/10.7208/chicago/9780226382777.001.0001/upso12889780226382463 
Shaffer, H. B., Fisher, R. N., \& Davidson, C. (1998). The role of natural history collections in documenting species declines. Trends in Ecology \& Evolution, 13(1), 27-30. https://doi.org/10.1016/S0169-5347(97)01177-4

Sheard, C., Neate-Clegg, M. H. C., Alioravainen, N., Jones, S. E. I., Vincent, C., MacGregor, H. E. A.,

Sheldon, K. S., Huey, R. B., Kaspari, M., \& Sanders, N. J. (2018). Fifty years of mountain passes: A perspective on Dan Janzen's classic article. The American Naturalist, 191(5), 553-565.

Shipley, J. R., Twining, C. W., Taff, C. C., Vitousek, M. N., Flack, A., \& Winkler, D. W. (2020). Birds advancing lay dates with warming springs face greater risk of chick mortality. Proceedings of the National Academy of Sciences, 117(41), 25590-25594. https://doi.org/10.1073/pnas.2009864117

Shirley, S. M., Yang, Z., Hutchinson, R. A., Alexander, J. D., McGarigal, K., \& Betts, M. G. (2013). Species distribution modelling for the people: Unclassified landsat TM imagery predicts bird occurrence at fine resolutions. Diversity and Distributions, 19(7), 855-866. https://doi.org/10.1111/ddi.12093 DiBattista, J., Gotanda, K. M., Francis, C. D., Hereford, J., Kingsolver, J. G., Augustine, K. E., Kruuk, L. E. B., Martin, R. A., Sheldon, B. C., Sletvold, N., Svensson, E. I., Wade, M. J., \& MacColl, A. D. C. (2017). Precipitation drives global variation in natural selection. Science, 355(6328), 959-962. https://doi.org/10.1126/science.aag2773

Slager, D. L. (2020). Seasonal and directional dispersal behavior in an ongoing dove invasion. Journal of Avian Biology, 51(2). https://doi.org/10.1111/jav.02332

Smith, A. C., \& Edwards, B. P. M. (2021). North American Breeding Bird Survey status and trend 
generalized additive model. Ornithological Applications, 123(duaa065). https://doi.org/10.1093/ornithapp/duaa065

1317 Smith, B. T., Gehara, M., \& Harvey, M. G. (2021). The demography of extinction in eastern North American birds. Proceedings of the Royal Society B: Biological Sciences, 288(1944), 20201945.

Smith, F. A., Betancourt, J. L., \& Brown, J. H. (1995). Evolution of Body Size in the Woodrat over the Past 25,000 Years of Climate Change. Science, 270(5244), 2012-2014.

Smith, R. J., \& Moore, F. R. (2005). Arrival timing and seasonal reproductive performance in a longdistance migratory landbird. Behavioral Ecology and Sociobiology, 57(3), 231-239. https://doi.org/10.1007/s00265-004-0855-9 ECOLOGICAL NICHES AND SPECIES’ DISTRIBUTIONAL AREAS. In Biodiversity Informatics (Vol. 2, pp. 1-10).

1333 Song, G., Zhang, R., Machado-Stredel, F., Alström, P., Johansson, U. S., Irestedt, M., Mays, H. L., https://kuscholarworks.ku.edu/bitstream/handle/1808/20560/soberon_interpretation.pdf?sequence $=1 \&$ isAllowed $=\mathrm{y}$ McKay, B. D., Nishiumi, I., Cheng, Y., Qu, Y., Ericson, P. G. P., Fjeldså, J., Peterson, A. T., \& Lei, F. (2020). Great journey of Great Tits (Parus major group): Origin, diversification and historical demographics of a broadly distributed bird lineage. Journal of Biogeography, 47(7), 1585-1598. https://doi.org/10.1111/jbi.13863

Staniczenko, P. P. A., Sivasubramaniam, P., Suttle, K. B., \& Pearson, R. G. (2017). Linking macroecology and community ecology: Refining predictions of species distributions using biotic interaction networks. Ecology Letters, 20(6), 693-707. https://doi.org/10.1111/ele.12770 
1341 Stanley, C. Q., MacPherson, M., Fraser, K. C., McKinnon, E. A., \& Stutchbury, B. J. M. (2012). Repeat tracking of individual songbirds reveals consistent migration timing but flexibility in route. PLOS

1344 Stanley, C. Q., Mckinnon, E. A., Fraser, K. C., Macpherson, M. P., Casbourn, G., Friesen, L., Marra, P. ONE, 7(7), e40688. https://doi.org/10.1371/journal.pone.0040688

Stevenson, R. D. (1985). The relative importance of behavioral and physiological adjustments controlling body temperature in terrestrial ectotherms. The American Naturalist, 126(3), 362-386. https://doi.org/10.1086/284423 P., Studds, C., Ryder, T. B., Diggs, N. E., \& Stutchbury, B. J. M. (2015). Connectivity of wood thrush breeding, wintering, and migration sites based on range-wide tracking. Conservation Biology, 29(1). https://doi.org/10.1111/cobi.12352

1354 Stralberg, D., Matsuoka, S. M., Hamann, A., Bayne, E. M., Sólymos, P., Schmiegelow, F. K. A., Wang, X., Cumming, S. G., \& Song, S. J. (2015). Projecting boreal bird responses to climate change:

1358 Sugai, L. S. M., Desjonquères, C., Silva, T. S. F., \& Llusia, D. (2020). A roadmap for survey designs in terrestrial acoustic monitoring. Remote Sensing in Ecology and Conservation, 6(3), 220-235.

1361 Suh, Y. H., Pesendorfer, M. B., Tringali, A., Bowman, R., \& Fitzpatrick, J. W. (2020). Investigating social and environmental predictors of natal dispersal in a cooperative breeding bird. Behavioral Ecology, 31(3), 692-701. https://doi.org/10.1093/beheco/araa007 Dhondt, A. A., Dietterich, T., Farnsworth, A., Fink, D., Fitzpatrick, J. W., Fredericks, T., Gerbracht, J., Gomes, C., Hochachka, W. M., Iliff, M. J., Lagoze, C., La Sorte, F. A., ... Kelling, 
S. (2014). The eBird enterprise: An integrated approach to development and application of citizen science. Biological Conservation, 169, 31-40. https://doi.org/10.1016/j.biocon.2013.11.003

1369 Sullivan, B. L., Wood, C. L., Iliff, M. J., Bonney, R. E., Fink, D., \& Kelling, S. (2009). eBird: A citizenbased bird observation network in the biological sciences. Biological Conservation, 142(10), 2282-2292. https://doi.org/10.1016/j.biocon.2009.05.006

1372 Taylor, S. A., White, T. A., Hochachka, W. M., Ferretti, V., Curry, R. L., \& Lovette, I. (2014). Climate-

1373 Mediated Movement of an Avian Hybrid Zone. Current Biology, 24(6), 671-676.

1374 https://doi.org/10.1016/j.cub.2014.01.069

1375 Terribile, L. C. (2012). Areas of climate stability of species ranges in the Brazilian Cerrado:

1376 Disentangling uncertainties through time. Natureza \& Conservação, 10(2), 152-159.

1377 https://doi.org/10.4322/natcon.2012.025

1378 Thomas, C. D., Franco, A. M. A., \& Hill, J. K. (2006). Range retractions and extinction in the face of

1379 climate warming. Trends in Ecology \& Evolution, 21(8), 415-416.

1380 https://doi.org/10.1016/j.tree.2006.05.012

1381 Thorup, K., Tøttrup, A. P., Willemoes, M., Klaassen, R. H. G., Strandberg, R., Vega, M. L., Dasari, H. P., Araújo, M. B., Wikelski, M., \& Rahbek, C. (2017). Resource tracking within and across continents in long-distance bird migrants. Science Advances, 3(1), e1601360. https://doi.org/10.1126/sciadv.1601360

1385 Thuiller, W., Lafourcade, B., Engler, R., \& Araújo, M. B. (2009). BIOMOD - a platform for ensemble forecasting of species distributions. Ecography, 32(3), 369-373. https://doi.org/10.1111/j.1600-

1388 Tingley, M. W., Darling, E., \& Wilcove, D. S. (2014). Fine- and coarse-filter conservation strategies in a 1389 time of climate change. Annals of the New York Academy of Sciences, 1322(The Year in Ecology 1390 and Conservation Biology), 92-109. https://doi.org/10.1111/nyas.12484 
1391 Tingley, M. W., Monahan, W. B., Beissinger, S. R., \& Moritz, C. (2009). Birds track their Grinnellian niche through a century of climate change. Proceedings of the National Academy of Sciences, 106(Supplement 2), 19637-19643. https://doi.org/10.1073/pnas.0901562106

1394 Tøttrup, A. P., Klaassen, R. H. G., Kristensen, M. W., Strandberg, R., Vardanis, Y., Lindström, Å., Rahbek, C., Alerstam, T., \& Thorup, K. (2012). Drought in Africa caused delayed arrival of European songbirds. Science, 338(6112), 1307-1307. https://doi.org/10.1126/science.1227548 https://doi.org/10.1111/j.1600-0706.2013.00399.x

1403 Urban, M. C., Zarnetske, P. L., \& Skelly, D. K. (2013). Moving forward: Dispersal and species interactions determine biotic responses to climate change. Annals of the New York Academy of Sciences, 1297, 44-60. https://doi.org/10.1111/nyas.12184 management on the extirpation risk of the Hawaiian common gallinule (Gallinula galeata sandvicensis) on the island of O'ahu. PeerJ, 6, e4990. https://doi.org/10.7717/peerj.4990

Visser, M. E. (2008). Keeping up with a warming world; assessing the rate of adaptation to climate

1412 Weiner, J. (1994). The Beak of the Finch: A Story of Evolution in Our Time.

1413 https://doi.org/10.5860/choice.32-1538

1414 Williams, J. W., Jackson, S. T., \& Kutzbach, J. E. (2007). Projected distributions of novel and 1415 disappearing climates by 2100 AD. Proceedings of the National Academy of Sciences, 104(14), 1416 5738-5742. https://doi.org/10.1073/pnas.0606292104 
1417 Winger, B. M., Auteri, G. G., Pegan, T. M., \& Weeks, B. C. (2019). A long winter for the Red Queen: Rethinking the evolution of seasonal migration. Biological Reviews, 94(3), 737-752.

1420 Wisz, M. S., Hijmans, R. J., Li, J., Peterson, A. T., Graham, C. H., \& Guisan, A. (2008). Effects of sample size on the performance of species distribution models. Diversity and Distributions, 14(5),

Wisz, M. S., Pottier, J., Kissling, W. D., Pellissier, L., Lenoir, J., Damgaard, C. F., Dormann, C. F., Forchhammer, M. C., Grytnes, J.-A., Guisan, A., Heikkinen, R. K., Høye, T. T., Kühn, I., Luoto, 763-773. https://doi.org/10.1111/j.1472-4642.2008.00482.x

Wogan, G. O. U., Voelker, G., Oatley, G., \& Bowie, R. C. K. (2020). Biome stability predicts population structure of a southern African aridland bird species. Ecology and Evolution, 10(9), 4066-4081. https://doi.org/10.1002/ece3.6175

1432 Wolfson, D. W., Fieberg, J. R., \& Andersen, D. E. (2020). Juvenile Sandhill Cranes exhibit wider ranging and more exploratory movements than adults during the breeding season. Ibis, 162(2), 556-562.

1435 Wüest, R. O., Bergamini, A., Bollmann, K., \& Baltensweiler, A. (2020). LiDAR data as a proxy for light availability improve distribution modelling of woody species. Forest Ecology and Management, 456, 117644. https://doi.org/10.1016/j.foreco.2019.117644 